UNIVERSITY OF ALBERTA

FACULTY OF ARTS

Department of Economics

Working Paper No. 2017-01

\title{
Carbon Pricing with an Output Subsidy under Imperfect Competition: The Case of Alberta's Restructured Electricity Market
}

\author{
David P. Brown \\ University of Alberta
}

\author{
Andrew Eckert \\ University of Alberta
}

\author{
Heather Eckert \\ University of Alberta
}

January 2017

Copyright to papers in this working paper series rests with the authors and their assignees. Papers may be downloaded for personal use. Downloading of papers for any other activity may not be done without the written consent of the authors.

Short excerpts of these working papers may be quoted without explicit permission provided that full credit is given to the source.

The Department of Economics, the Institute for Public Economics, and the University of Alberta accept no responsibility for the accuracy or point of view represented in this work in progress. 


\title{
Carbon Pricing with an Output Subsidy under Imperfect Competition: The Case of Alberta's Restructured Electricity Market
}

by

\author{
David P. Brown, ${ }^{\dagger}$ Andrew Eckert ${ }^{\ddagger} \quad$ Heather Eckert*
}

\begin{abstract}
In this paper, we examine the use of carbon pricing and an output-based subsidy in a market with imperfect competition. We consider a carbon pricing policy in Alberta's electricity market as a case study. This policy consists of two phases. In the first phase, the carbon price is doubled with the output subsidy being based on a fraction of facility-level emission intensity. In the second phase, the carbon price will remain constant, while the output subsidy is altered to be uniform across assets and based on the emissions intensity of an efficient natural gas asset. Using a model of oligopoly competition, we simulate the shortrun impacts of the two phases on electricity prices, emissions, and unit and firm-level profitability. We find that the mechanisms by which electricity prices and emissions change in response to carbon pricing differ depending on whether the market is perfectly competitive or oligopolistic. We demonstrate that regardless of market structure, changing the basis of the output subsidy has substantially larger effects than a doubling of the carbon price. The estimated effects of carbon pricing vary as the firms' generation portfolios change.
\end{abstract}

Keywords: Electricity, Market Power, Carbon Price, Pass-Through

JEL Codes: D43, L51, L94, Q40, Q58

January 2017

$\dagger$ Department of Economics, University of Alberta, Edmonton, Alberta T6G 2H4 Canada (dpbrown@ualberta.ca).

$\ddagger$ Department of Economics, University of Alberta, Edmonton, Alberta T6G 2H4 Canada (aeckert@ualberta.ca).

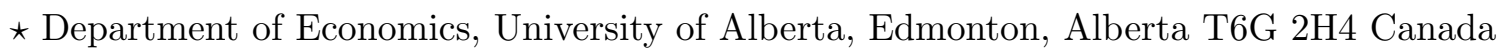
(heather.eckert@ualberta.ca).

Acknowledgments We would like to thank Brandon Schaufele, Blake Shaffer, Trevor Tombe, and seminar participants at the 2016 Canadian Resource and Environmental Economics Conference for their helpful comments and suggestions. We also would like to thank Yuan Bian for his helpful research assistance. This research project was funded by the Economics and Environment Policy Research Network (EEPRN) at the University of Ottawa's Institute of the Environment. 


\section{Introduction}

Mitigating climate change has become an increasingly important and contentious economic issue. Environmental regulations that place a price on carbon dioxide emissions have been proposed or implemented in a number of jurisdictions. The effects of carbon pricing on the electricity industry has been a major focal point in these discussions because of its sizable production of greenhouse gas (GHG) emissions. For example, in the U.S. in 2014, 30\% of GHG emissions came from electricity production, while in Europe electricity, gas, steam, and air conditioning accounted for 27\% of GHG emissions in 2013 (EPA, 2016, Eurostat, 2016).

A key complication regarding the introduction of carbon pricing in market-based restructured electricity markets is the presence of imperfect competition. It is well recognized that particular features of wholesale electricity markets, including the inelasticity of demand and the inability to store electricity, create a strong potential for market power (e.g., see Borenstein et al., 1999). Imperfect competition complicates the design of carbon pricing, as it influences how such pricing effects wholesale prices and emissions. While in a perfectly competitive market price pass-through depends upon the elasticities of supply and demand, in an oligopolistic market the price pass-through also depends on individual firm's strategic behavior (see Sijm et al. (2012) for a discussion). Likewise, in a perfectly competitive industry, carbon pricing reduces emissions of all firms. This result may not hold under imperfect competition.

Carbon pricing in electricity markets has often been introduced alongside some form of output-based subsidy or permit allocation. Recent literature has shown that in the presence of an additional market distortion, such as imperfect competition, a two-part policy that includes a price on emissions and a subsidy on output can be welfare improving. For example, Gersbach and Requate (2004) consider emissions taxes in the presence of symmetric Cournot competition and show that the emissions price can generate efficient emission levels while an exogenous output subsidy can correct the market power distortion. However, there has been limited empirical evidence on the effects of output-based subsidies coupled with carbon pricing.

In this paper, we simulate the effect of proposed changes to carbon pricing and output-based subsidies in Alberta's wholesale electricity market. Under the initial carbon pricing policy, generators face a carbon price (per ton of $\mathrm{CO}_{2} \mathrm{e}$ ) and receive an output subsidy based on their historical baseline emissions intensity (tons of $\mathrm{CO}_{2} \mathrm{e}$ per MWh). This policy effectively operates as an emissions tax because a generator's emissions intensity is inflexible in the short-run. The emission price faced by firms will change in two phases. In the first phase, the carbon price will double from $\$ 15 / \mathrm{tCO}_{2} \mathrm{e}$ to $\$ 30 / \mathrm{tCO}_{2} \mathrm{e}$ and the outputbased subsidy will fall to be a smaller proportion of an asset's baseline emissions intensity. In the second phase, the carbon price remains unchanged, but the output subsidy for all generation units is equal to the emissions intensity of a benchmark natural gas asset. As a result, the second phase significantly increases the net carbon costs of coal assets relative to natural gas plants. This provides an opportunity to examine the relative effects of changes to the carbon price versus changes to output subsidies.

In order to carry out this analysis, we develop a model of the restructured wholesale electricity market in Alberta, using data for the period from 2014 to 2015. In our imperfectly competitive Cournot model, five large strategic firms and a competitive fringe compete to supply electricity. We then use our model to simulate the short-run market effects on equilibrium prices, quantities, and emissions of both phases 
of the proposed policy change, under our Cournot model and also assuming perfect competition.

We find that the estimated effects of the carbon pricing policy on market outcomes, firm behavior, and emissions vary substantially by the nature of market competition. Under perfect competition the price effect and emissions reductions primarily depend on the level of market demand and the technology of the marginal asset setting the market-clearing price before and after the carbon pricing change. Our results demonstrate that, in addition to these factors, under Cournot competition the rate of pass-through and emissions reductions reflect strategic considerations such as the distribution of generation technologies between the large firms and a price-taking fringe competitor and whether the competitive fringe's generation units are operating at maximum capacity. Similar to Mansur (2007), for each policy simulation we find that carbon emissions are lower and prices are higher under oligopoly market competition as the relatively dirtier large firms withhold output to elevate market prices.

We find that the change in the nature of the output-based subsidy reduces emissions by more than four times the amount of the doubling of the carbon price. This is driven by the asymmetric effect of the change in the output subsidy on the marginal cost of coal assets which leads to greater substitution from coal to natural gas assets. This effect also results in a reduction (increase) in the profitability of coal (natural gas) assets. The impact of carbon pricing on firm-level profitability is complicated by the fact that firms own a diverse portfolio of assets. These findings demonstrate that the design of the output subsidy can have substantial effects on the performance of environmental regulations in restructured electrity markets.

Our research makes a number of contributions to the existing literature. First, to our knowledge, it is the first empirical study of an emissions tax and output-based subsidy policy, as previous analyses are either theoretical, qualitative, or focus on emissions trading schemes. Second, the two phases of the Alberta policy allow us to compare the effects of increasing the carbon price and changing the basis of the output subsidy. Finally, while previous studies on pass-through in electricity markets often focus on how the policy affects marginal costs of units and and the "merit order" (the sequence of generating units from lowest to highest marginal cost), our analysis also considers the effect of market power execution.

The remainder of this paper will proceed as follows. The relevant literature is reviewed in Section 2. The Alberta electricity market and carbon pricing policy are discussed in Section 3. A model of Alberta's wholesale electricity market is given in Section 4. Our empirical methodology and data are presented in Section 5. Section 6 presents the results of our empirical model. Section 7 concludes.

\section{Related Literature}

\subsection{Economic Theory of Emissions Taxes with Imperfect Competition}

In this section, we briefly discuss the key determinants of price pass-through and emissions changes from an emissions tax under Cournot competition. 


\subsubsection{Price Pass-Through}

We focus on price pass-through as the derivative of price with respect to marginal cost and suppose that all firms in the market face a tax of $\$ t /$ unit. $^{1}$ First, suppose that the market is perfectly competitive, with a supply curve given by $S(Q)$ and the inverse downward sloping market demand curve is given by $D(Q)$. As is well known, pass-through (the derivative of the equilibrium price with respect to the tax) depends on the relative elasticities of the supply and demand curves:

$$
\frac{d P}{d t}=\frac{1}{1+\frac{\epsilon_{D}}{\epsilon_{S}}},
$$

where $\epsilon_{D}$ and $\epsilon_{S}$ are the own price elasticities of demand and supply. Hence, more of the tax will be passed through into price as demand becomes less elastic and as supply becomes more elastic.

Now consider an $N$ firm symmetric Cournot model where each firm $i$ has the cost function $C\left(q_{i}\right)$ and $Q=\sum_{i=1}^{N} q_{i}$. As is shown in RBB Economics (2014), we can write:

$$
\frac{d P}{d t}=\frac{N P^{\prime}(Q)}{(N+1) P^{\prime}(Q)+Q P^{\prime \prime}(Q)-N C^{\prime \prime}(Q / N)} .
$$

In contrast to the perfectly competitive model, here the pass-through of $t$ depends on the curvature of the demand and cost functions, as well as on the number of firms. If demand is linear and marginal costs are constant, $\frac{d P}{d t}=\frac{N}{N+1}$. Passthrough is less than 100\%, but converges on $100 \%$ from below as $\mathrm{N}$ increases. If demand is concave, $\frac{d P}{d t}<\frac{N}{N+1}$, while if demand is convex, $\frac{d P}{d t}>\frac{N}{N+1}$ It is possible that when demand is sufficiently convex, pass-through may exceed $100 \%$.

The above discussion looked at the pass-through of a small increase in a tax. While generally focused on symmetric models, the models can be adapted to asymmetric firms. However, an analysis of the price pass-through of Alberta's carbon tax is complicated for at least two reasons. First, the above discussion considers a small symmetric increase in the tax that applies to all units of output. However, a sufficiently large carbon price applying asymmetrically to different generation technologies can change the ordering of assets' marginal cost of production. ${ }^{2}$ This is likely the case in Alberta.

Secondly, in our empirical model a firm has several generating units, each with a different constant marginal cost up to maximum capacity. Often in equilibrium, a firm will be producing to capacity with its last unit called upon to supply electricity (i.e., its marginal unit). As such, the last unit of the current generating asset can have a marginal cost below marginal revenue, while the first unit of the next asset in the merit (cost) order has a marginal cost above marginal revenue. This will affect pass-through, since in this case a small increase in the tax will not affect the firm's output. This effect is most important when a firm experiences a large jump in marginal cost from one asset to the next, as can arise in the transition from coal to natural gas. If in the baseline equilibrium the firms are producing up to their maximum capacity from coal, but not using natural gas generators, then the addition of a tax that increases the marginal cost of coal generation by a small amount, but not enough to change the order of assets in the merit (cost) order, could result in zero pass-through.

As a result of these considerations, the degree to which electricity prices increase with changes to

\footnotetext{
${ }^{1}$ This analysis can be extended to consider a tax that is imposed asymmetrically across firms. More detailed treatments can be found in Sijm et al. (2012), Weyl and Fabinger (2013), and RBB Economics (2014)

${ }^{2}$ See Sijm et al. (2012) for a discussion.
} 
carbon pricing becomes an empirical issue. Under perfect competition, there are two mechanisms by which carbon pricing will increase the wholesale electricity price. First, the marginal costs of the last unit called upon to supply electricity will shift up, and the resulting price increase will depend on the slopes of demand and marginal cost functions. Second, changes in the cost ordering of the generation assets may arise, potentially changing the technology of the marginal (price-setting) generator and those who are called upon to supply electricity. A third mechanism arises under imperfect competition as the market power incentives of firms can change in response to carbon pricing.

\subsubsection{Emission Effects}

In a perfectly competitive industry in which the only distortion is pollution, the first-best outcome can be implemented using an emissions tax equal to marginal damages (a Pigovian tax). Such a tax reduces both firm-level and aggregate output, emissions, and profits. These results, however, may not hold in a Cournot oligopoly. ${ }^{3}$ If firms are symmetric, firm-level output and emissions fall with an emissions tax, implying that aggregate emissions also fall. However, when firms are asymmetric in either cost or emissions intensity, an emissions tax need not reduce aggregate emissions. ${ }^{4}$ With asymmetry, aggregate output is decreasing in the emissions tax but the output, emissions, and profit of some firms may increase. This result only requires that marginal costs be sufficiently asymmetric across firms and that the marginal cost differential not be the same as the difference in emissions intensities (Requate, 2006). Given the differences in marginal generating costs and emissions intensities across generating units in Alberta, it is reasonable to expect that the effect of carbon pricing on firm-level output and emissions may take different signs. The more perverse result that aggregate emissions increases with the emissions tax also requires the curvature of the demand function be sufficiently extreme (Levin, 1985).

\subsection{Empirical Literature on Emissions Pricing in Electricity Markets}

Most studies analyzing the effect of carbon policies on the electricity sector focus on emissions trading systems (ETS) in California or the European Union (EU ETS). For example, Sijm et al. (2012) analyze the EU ETS market and demonstrate that the change in electricity prices due to the carbon policy depends critically on the nature of firm competition and demand assumptions. A number of studies examine pass-through in a reduced-form setting and find rates ranging from well below unity to $20 \%$ above full pass-through (e.g., see Sijm et al. (2006a)). Fabra and Reguant (2014) go beyond measuring pass-through rate and disentangle its components using firm-level data on Spanish electricity generators. The authors find a pass-through rate of approximately $80 \%$. Their simulations suggest that the pass-through rate is less than $100 \%$ because demand is not perfectly inelastic, firms exercise market power, and the substitution from coal to natural gas is more pronounced than if the market were perfectly competitive.

Mansur (2007) examines the effect of imperfect competition on the functioning of emissions policies in the US electricity sector. ${ }^{5}$ Using the simultaneous introduction of emissions reduction policies and deregulation of electricity in the PJM market, Mansur undertakes the following analysis. Beginning at

\footnotetext{
${ }^{3}$ See Requate (2006) for a comprehensive survey of environmental policy with imperfect competition

${ }^{4}$ This is true even in the emissions tax is proportional to emissions intensity as it the case in Alberta. See Levin (1985) for a discussion.

${ }^{5}$ Newcomer et al. (2008) use a least-cost dispatch model to simulate the short-run impacts of a carbon pricing on the US electricity sector, assuming markets are perfectly competitive.
} 
a status quo of no policy within a perfectly competitive industry, he simulates what the effect of the air pollution policy would be if the industry remained perfectly competitive compared to the observed outcome of the policy with imperfect competition. Although Mansur considers a permit trading scheme, his assumption of a perfectly competitive permit market means that the permit market generates the same outcomes as an emissions tax. Mansur finds that emissions reductions were over $30 \%$ larger with imperfect competition than would have been the case under perfect competition as relatively dirtier firms withhold output to elevate market-clearing prices. This highlights the importance in accounting for market structure when considering the efficacy of environmental regulations.

\subsection{Emissions Pricing with Output Subsidies}

The combination of a marginal price on emissions with a subsidy on output has become increasingly common and can take on a number of forms: an emissions tax with output-based refunding, a tradable emissions performance standard, or a cap-and-trade system with output-based permit allocation. ${ }^{6}$ When emissions tax revenue is refunded based on output, such as Sweden's $\mathrm{NO}_{x}$ tax on large stationary sources, the refund acts as a subsidy on output (Sterner and Isaksson, 2006). A tradable emissions performance standard sets an allowable emissions intensity and firms with lower intensity can earn credits which can be sold to firms that fail to meet the standard. The resulting marginal price of emissions is equal to the price on credits and the allowable emissions intensity represents an implicit output subsidy (Rivers and Jaccard, 2010). ${ }^{7}$ Finally, cap-and-trade systems with output-based permit allocations also implicitly subsidize output. Variations of such allocation systems are used for some industries and member states under the EU ETS and have been proposed in Australia as well as in the U.S. under the Waxman-Markey clean energy bill. ${ }^{8}$

The motivation for pairing emissions pricing with output subsidies is often to mitigate the cost burden of regulation, particularly in trade exposed sectors. With perfect competition and no other distortions, output-based subsidies reduce welfare by generating inefficiently high output. However, in a second best setting, a two-part policy may be welfare improving (Fischer, 2001). Of particular importance for carbon pricing are distortions from incomplete regulatory coverage and imperfect competition. Given the global nature of greenhouse gas emissions, domestic regulation of $\mathrm{CO}_{2}$ emissions is incomplete. As well, a significant portion of emissions arise from imperfectly competitive industries such as electricity. Our focus here is on the role of imperfect competition.

Imperfectly competitive polluting industries exhibit two distortions: inefficiently low output and inefficiently high emissions. Gersbach and Requate (2004) show that in a symmetric Cournot duopoly, a tax and refund scheme can generate the first-best outcome if the distortion from pollution is more damaging than the distortion from imperfect competition. In particular, the share of tax revenue to be refunded is chosen to induce efficient production while the emissions price is chosen set to induce efficient abatement. However, with asymmetric costs, a uniform tax and refund cannot implement the first-best outcome. ${ }^{9}$

\footnotetext{
${ }^{6}$ See Fischer (2001) for a discussion of the relationship between tradable performance standards, emissions tax/rebate systems, and tradable permits with output-based allocations.

${ }^{7}$ In fact, tradable performance standard based on other metrics of performance can also represent implicit subsidies. For example, the phase out of lead in U.S. gasoline in the early 1980s and proposed clean energy standards for electricity implicitly subsidize clean production (Fischer, 2001; Paul et al., 2013).

${ }^{8}$ There is an extensive literature analyzing the effects of permit allocations (e.g., see Fowlie and Perloff (2013).

${ }^{9}$ In the case of a revenue neutral policy, output-based refunds are endogenous and first-best cannot be implemented (see
} 
Most empirical analyses of emissions pricing with output subsidies focus on output-based allocations under cap-and-trade systems. Fowlie et al. (2016) examine the Portland cement industry and finds that the implicit production subsidy of (updated) output-based allocation mitigates both the market power and emissions leakage distortions. With respect to the energy industry, Golombek et al. (2011) use a multi-sector general equilibrium model to examine different allocation rules under the EU ETS and their impact on the energy market in Western Europe. They find that relative to grandfathering, output-based allocation leads to a higher emissions price, a lower electricity price, and greater gas production. To our knowledge, Sterner and Isaksson (2006) is the only study of a rebated emissions tax. The authors informally examine the Swedish NOx tax which is rebated to firms in proportion to their energy output. They find suggestive evidence that it has been effective at reducing emissions and emission intensities.

While the theoretical literature suggests a role for output-based subsidies in the presence of imperfect competition, understanding how a specific subsidy scheme will impact market outcomes in a real-world setting is complicated. The theoretical models tend to focus on either symmetric firms, and suppose that subsidies are granted at the firm-level. In contrast, in the Alberta setting, subsidies are at the level of the generating asset, and based on the technology and emissions intensity of the asset. Firms however make firm-level decisions and have diverse generating portfolios with a wide range of technologies. A change to the output subsidy mechanism can have complex effects on the firm-level marginal cost curves. As a result, it is difficult to predict how such changes will pass-through to market outcomes and so, price pass-through and the effects on emissions is an empirical question.

\section{Alberta's Electricity Market}

\subsection{Market Structure and Design}

Alberta's wholesale market consists of a single hourly spot market that takes the form of a uniform-priced multi-unit auction. In each hour, firms submit price-quantity offers for each of their generation units. These offers represent the price at which the firm is willing to supply a certain amount of electricity from a given unit. Throughout the hour, the system operator dispatches firms in order of their offers to meet market demand. At any moment, the system marginal price is the price of the highest offer called upon to supply (dispatch) electricity. The marginal generation unit is the last asset dispatched. The pool price is the average of the system marginal prices throughout the hour. At the end of the hour, the pool price is paid to each firm for the electricity it provided in the hour.

Alberta's wholesale electricity market has several features that simplify its analysis relative to restructured electricity markets in other jurisdictions. First, Alberta's market is energy-only, meaning that firms receive revenue only for the energy they provide, and are not paid to maintain capacity. ${ }^{10}$ Second, Alberta's wholesale market features a uniform wholesale price that applies to all generators who are dispatched regardless of location. This is in contrast to jurisdictions which apply locational (nodal) pricing to reflect transmission congestion. Finally, Alberta's legislation and regulations do not prohibit the exercise of unilateral market power (MSA, 2011), and there are no limitations to the extent a firm can unilaterally mark up its offers above marginal cost (other than the market's price ceiling of $\$ 999.99 / \mathrm{MWh}$ ).

Fischer (2011)).

${ }^{10}$ Similar market designs exist in Texas, Australia, Germany, and Northern Europe's Nord Pool (Pfeifenberger et al., 2009). 
Table 1 provides details regarding the degree of market concentration and observed electricity generation by technology in Alberta. Generation capacity remains relatively concentrated within the five largest firms, while a fringe of over twenty-five firms own the residual generation capacity. In the period of our study, electricity is primarily generated by coal and natural gas generation units.

Table 1: Alberta Market and Firm Characteristics

\begin{tabular}{lcccccc}
\hline \hline \multicolumn{2}{l}{ Panel A: Market Shares of Generation Capacity by Firm and Year (\%) } & & \\
\hline & TransCanada & TransAlta & ENMAX & ATCO & Capital Power & Fringe \\
\hline 2014 & 17.9 & 15.5 & 12.7 & 11.8 & 11.3 & 30.8 \\
2015 & 16.5 & 14.0 & 17.0 & 10.5 & 10.9 & 31.1 \\
\hline
\end{tabular}

Panel B: Market Shares of Electricity Generation by Fuel Type and Year (\%)

\begin{tabular}{lccccc}
\hline & Coal & Natural Gas & Wind & Hydro & Other \\
\hline 2014 & 55.3 & 35.0 & 4.3 & 2.3 & 3.1 \\
2015 & 50.7 & 39.5 & 4.7 & 2.1 & 3.0 \\
\hline
\end{tabular}

Panel C: Coal Capacity in MW and as a Percentage of Total Capacity, by Firm and Year (\%)

\begin{tabular}{lcccccc}
\hline & TransCanada & TransAlta & ENMAX & ATCO & Capital Power & Fringe \\
\hline 2014 & $2,071(81.4)$ & $627(28.3)$ & $1,134(62.7)$ & $321(19.2)$ & $1,213(75.4)$ & $906(20.6)$ \\
2015 & $2,171(83.2)$ & $627(28.2)$ & $1,134(42.0)$ & $321(19.3)$ & $1,213(70.4)$ & $806(16.3)$ \\
\hline
\end{tabular}

Notes: Data on generation capacity are obtained from MSA $(2014,2015)$. Generation data by fuel source are obtained from AUC (2016). Other generation category consists largely of biomass units. In Panel C, data reported as MW (\%).

In order to understand the effect of carbon pricing on firm-level profits, and on market outcomes when the market is imperfectly competitive, it is necessary to consider the relative importance of coal technology in the portfolios of individual firms. To this end, Panel $\mathrm{C}$ reports the total MW and percentage of each firm's capacity that is based on coal technology. Coal represents at least $40 \%$ of generation capacity for three of the five largest firms, with two firms relying on coal for over $70 \%$ of their capacity. As a result, we should expect that the effect of carbon pricing changes on profitability may be greatest for these firms. As well, their large reliance on coal suggests that coal may be the marginal technology for these firms for a large proportion of hours.

One complication in Alberta's electricity market, as well as in other jurisdictions, is the presence of forward transactions. In addition to buying and selling in the spot market, firms can engage in transactions outside of, and in advance of, the spot market. Forward contracts can reflect retail commitments for vertically integrated utilities (Bushnell et al., 2008), regulatory requirements imposed on dominant generators (Frutos and Fabra, 2012), or competitive arrangements between generators and distribution utilities (Crew and Kleindorfer, 2002). In Alberta, forward trading reflects competitive arrangements between generation companies and distribution retailers. ${ }^{11}$ It is well established that the presence of forward contracting reduces the incentives of firms to exercise market power in the spot market (Bushnell et al., 2008; Brown and Eckert, 2016). There is limited public information regarding firms' forward contracts. Similar to Hortascu and Puller (2008) and Reguant (2014), we use observed firm behavior and a structural assumption on the nature of competition to calibrate baseline levels of firms' forward commitments. ${ }^{12}$

\footnotetext{
${ }^{11}$ See MSA (2010) and Brown and Eckert (2016) for a detailed discussion on forward contracting in Alberta.

${ }^{12}$ Section 6.5 demonstrates the robustness of our model results to adjustments in firms' forward contracted quantities.
} 


\subsection{Carbon Pricing Policy}

Since 2007, large emitters in Alberta (with emissions in excess of 100,000 tonnes of $\mathrm{CO}_{2}$ e per year) have been governed by the Specified Gas Emitters Regulation (SGER). SGER is a tradable emissions performance policy under which facilities pay a price per unit of emissions intensity (tonnes of CO2 equivalent emissions per MWh) greater than a percentage of their historical baseline emissions intensity and can sell credits equal to any improvement relative to this threshold. ${ }^{13}$ In practice for electricity generators, this policy amounts to a carbon price per tonne of $\mathrm{CO}_{2} \mathrm{e}$, coupled with a subsidy that is proportional to a facility's historical baseline emissions intensity.

Under SGER prior to 2016, large emitters were given credits equal to $88 \%$ of their baseline emissions and the price of carbon was $\$ 15 / \mathrm{tCO}_{2} \mathrm{e}$. Our focus in this paper is on changes occurring in two distinct phases from 2016-2018. ${ }^{14}$ The first, taking place under SGER in 2017, involved an increase in the carbon price from $\$ 15 / \mathrm{tCO}_{2} \mathrm{e}$ to $\$ 30 / \mathrm{tCO}_{2} \mathrm{e}$, coupled with a reduction of a facilities emissions credits to $80 \%$ of its baseline. The second phase begins in 2018 and corresponds to the Carbon Competitiveness Regulation (CCR) recommended by the Climate Change Advisory Panel (Government of Alberta, 2015). Under CCR, the carbon price will remain unchanged, but the manner of allocating credits changes; a facility's emissions credits will no longer be based on its own historical emissions intensity, but rather on the intensity of a representative efficient natural gas asset.

To understand better how these changes affect the marginal costs of generators, consider a generic tradable emissions performance policy in which firm $i$ pays a price of carbon $\left(\$ P^{C} / \mathrm{tCO}_{2}\right)$ when their emissions intensity $\left(E I_{i t}\right)$ is greater than their allocation of emissions intensity credits. The output-based allocation (OBA) of credits can take two forms: a proportion $\alpha$ of facility-level baseline emissions intensity $\left(B E I_{i}\right)$ and a constant $T>0$. Under this policy, in year $t$, firm $i$ will pay a per MWh emissions price of:

$$
p^{C}\left[E I_{i t}-\alpha B E I_{i}-T\right] .
$$

Prior to $2016, p^{C}=15, \alpha=0.88$, and $T=0$. This implies for example that a coal facility with current and baseline emissions intensity equal to 1 would face a net emissions price of $\$ 1.8 / \mathrm{MWh}$. In contrast, a natural gas unit who's current and baseline emissions intensity is only 0.5 would face a net emissions price of only $\$ 0.90 / \mathrm{MWh}$. Under the first phase of policy changes beginning in $2017, p^{C}$ is increased to 30 , while $\alpha$ is reduced to $0.8 .^{15}$ As a result, the emissions costs of our example coal and natural gas units above would increase to $\$ 6 / \mathrm{MWh}$ and $\$ 3 / \mathrm{MWh}$ respectively. In the second phase, the carbon price remains unchanged but firms are given credits equal to the emissions intensity of an efficient benchmark natural gas asset rather than a fraction of facility-level baseline intensity. The benchmark efficiency is expected to be 0.375 , so that in $2018, p^{C}=30, \alpha=0$ and $T=0.375$. For our ongoing example, the marginal emissions cost would increase dramatically to $\$ 18.75 / \mathrm{MWh}$ for the coal unit, but

\footnotetext{
${ }^{13}$ The baseline emissions intensity is equal to a facility's average emissions intensity between 2003 and 2005. See Leach (2012) for a detailed discussion of SGER.

${ }^{14}$ There are also changes to the carbon policy for small emitters that face no regulation prior to 2016. However, such units consist of small natural gas units which generate less than $1.2 \%$ of output in our sample. For ease of exposition, our discussion here focuses on large emitters, while our simulations incorporate the carbon price faced by all units.

${ }^{15}$ There is also an intermediate change to SGER in 2016 where firms pay $\$ 20 / \mathrm{tCO}_{2} \mathrm{e}$ and receive an output subsidy of $85 \%$ of facility baseline emissions intensity. For illustrative purposes, we do not analyze this intermediate change because it has similar effects as the policy update observed in 2017.
} 
only to $\$ 3.75 / \mathrm{MWh}$ for the natural gas unit.

Our application of SGER and CCR to Alberta's electricity market is based on the assumption that a generating asset's emissions intensity is primarily determined by its unit-level efficiency which for established generating units can be taken as fixed and exogenous. ${ }^{16}$ This has two implications that simplify our analysis. First, it means that facilities cannot earn credits under the tradable emission performance standard by reducing their emissions intensity in response to the policy, so that the output-based allocation simply reduces the total emissions charge paid by a facility. The assumption that firms cannot adjust emissions intensity in response to the policy is particularly reasonable for our analysis, which focuses on the short-run impacts of policy changes.

Second, the observation that the emissions intensity of electricity generating units depends on the heat rate of the plant which is difficult to change allows us to suppose that for asset $j$ owned by firm $i$, $E I_{i}^{j}=B E I_{i}^{j}$. Reported emissions data from Alberta Environment and Parks provide broad support for this assumption. The average emissions intensity over reporting facilities in 2014 and the average baseline emissions intensity established in 2003 to 2005 for the same group of firms are both equal to $0.86 .{ }^{17}$ Consequently, the tradable emissions performance standard applied to electricity generators represents an emissions tax under which firms pay $p^{E}=p^{C}(1-\alpha) E I_{i}^{j}-T$ per unit of output from asset $j$. Note that this is simply a linear emissions tax schedule under which the price of emissions is an increasing function of emissions intensity. Changes in the $p^{C}$ and $\alpha$ change the slope of the tax function while changes in $T$ shift the intercept of the tax function.

The different carbon pricing schemes, and their effect on the emissions cost per MWh of electricity of an asset with an emissions intensity of $E I_{i}^{j}-T$, are summarized in Table 2. In the table, SGER15 is the benchmark observed pricing regime in 2014-2015, SGER17 is the pricing regime faced in 2017 (Phase 1), and CCR is the pricing regime in 2018 (Phase 2). $P^{C}$ is the carbon price, OBA refers to the output-based allocation of credits, and $p^{E}$ is the emissions price per MWh of electricity. ${ }^{18}$

Table 2: Carbon Pricing for Electricity Generators in

Alberta

\begin{tabular}{ccccc}
\hline Year & Scenario & $P^{C}$ & OBA & $P^{E}$ \\
\hline 2015 & SGER15 & 15 & $0.88 \mathrm{EI}_{i}$ & $15 \times 0.12 \times E I_{i}$ \\
2017 & SGER17 & 30 & $0.80 \mathrm{EI}_{i}$ & $30 \times 0.20 \times E I_{i}$ \\
2018 & CCR & 30 & 0.375 & $30 \times\left(E I_{i}-0.375\right)$ \\
\hline Notes: & $P^{C}$ is given in $\$ / \mathrm{CO}_{2} \mathrm{e}$ and $P^{E}$ is given in $\$ / \mathrm{MWh}$.
\end{tabular}

To illustrate better the asymmetric effect of the proposed changes to $\alpha$ and $T$ effect on generating assets of different emissions intensity, Figure 1 plots the emissions cost per MWh of generation as a function of emissions intensity under each scenario. The ranges of coal and natural gas emissions intensities are highlighted. The two phases of the policy represent two approaches to reduce the cost burden associated with the doubling of the carbon price. SGER17 increases the slope of the tax schedule so that all firms

\footnotetext{
${ }^{16} \mathrm{~A}$ unit's efficient rate (heat-rate) is the rate at which it can convert fuel into electricity.

${ }^{17}$ As a further check, for each generation unit in our sample, we use data from 2008 to 2014 on facility-level reported emissions data from Environment and Climate Change Canada's National Pollutant Release Inventory and observed output to compute the implied asset-level heat-rates. We do not observe any systematic improvements in the implied asset-level heat-rates.

${ }^{18}$ See Section 5.2 for additional details on the computation of marginal environmental compliance costs under each policy.
} 
face a higher emissions price than under SGER15, but the marginal cost of being more emissions intense $\left(p^{C}(1-\alpha)=6\right)$ remains low. CCR reduces the intercept of the tax schedule by 11.25 (or $30 \times 0.375$ ). Relative to SGER15 and SGER17, the emissions price per MWh of electricity falls for the relatively clean generators (i.e., natural gas assets), but substantially increases for all coal plants.

Figure 1: Emissions Price per MWh of generation vs. Emissions Intensity

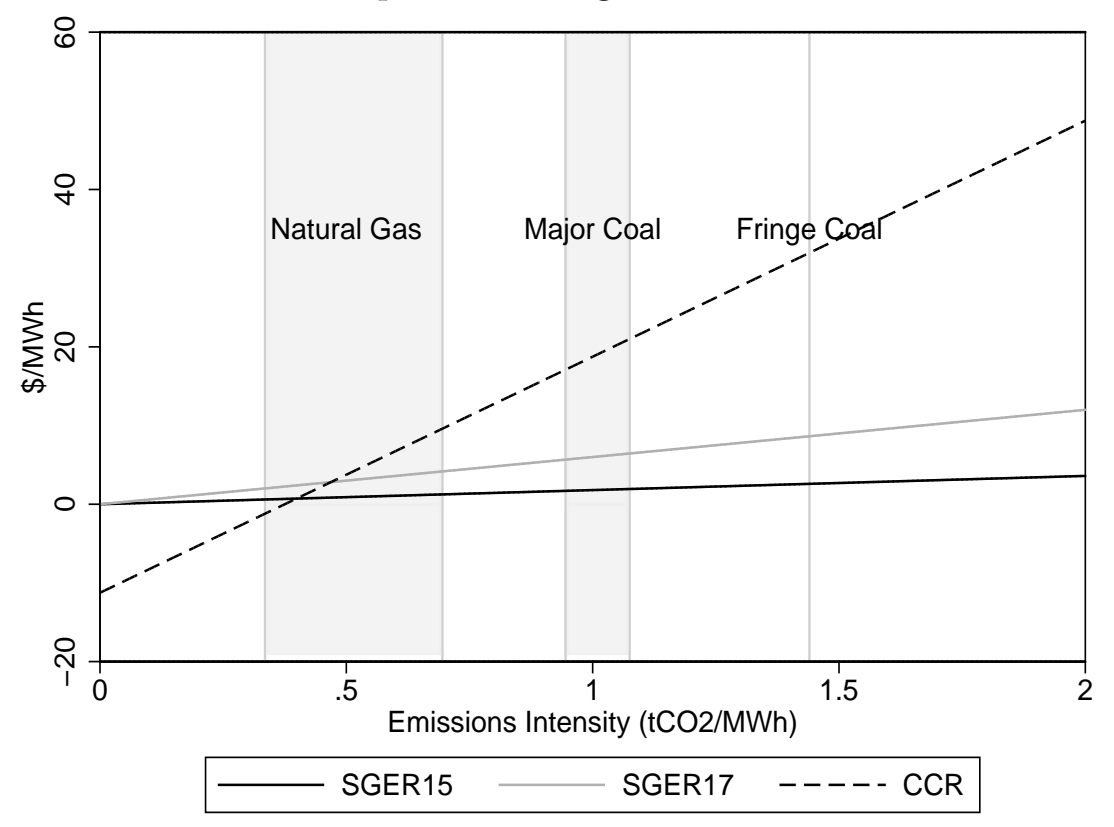

\section{Model}

We consider a model of wholesale electricity market competition where $N=6$ firms simultaneously choose hourly quantities to supply to the market. We assume that wholesale electricity is a homogeneous product with a uniform price. For each period $t=1,2, \ldots, T$, each firm $i$ competes in the spot market by making its electricity production decisions $q_{i t}^{j}$ for each of its assets $j \in G_{i t}$, where $G_{i t}$ denotes the set of firm $i$ 's generation units in period $t$. For each of its assets, firm $i$ 's output choice is constrained above by its maximum capacity $q_{i t}^{j, \text { Max }}$ and below by its minimum level of stable generation $\psi_{i t}^{j} q_{i t}^{j, \text { Max }} \geq 0$ that must be operating in order to satisfy engineering constraints where $1>\psi_{i t}^{j} \geq 0$.

Define $C_{i t}^{j}\left(q_{i t}^{j}\right)$ to be firm $i$ 's cost of producing $q_{i t}^{j}$ units of electricity from asset $j \in G_{i t}$. In addition to dispatchable (controllable) output, each firm $i$ has a certain level of must-run generation $q_{i t}^{M R} \geq 0$ that has zero marginal cost (e.g., wind output). In period $t$, a firm's total output is $q_{i t}=\sum_{j \in G_{i}} q_{i t}^{j}+q_{i t}^{M R}$ and aggregate market output is $Q_{t}=\sum_{i=1}^{6}\left(\sum_{j \in G_{i}} q_{i t}^{j}+q_{i t}^{M R}\right)$. Define $P_{t}\left(Q_{t}\right)$ to be the inverse residual demand function that represents market-level demand net of imports from neighboring provinces.

At each period $t$, firm $i$ has a certain level of forward (retail) committed output $q_{i t}^{f} \geq 0$. Define $P_{i t}^{f}$ to be firm $i$ 's forward contracted price level. We assume that forward prices and quantities are taken as given for each firm $i=1,2, \ldots, 6$ when firms make their spot market production decisions.

Firm $i$ chooses its quantity of output for each of its assets $j \in G_{i t}$ in period $t$ to its maximize profit subject to its lower and upper production constraints: 


$$
\begin{array}{rrll}
\underset{q_{i t}^{j} \forall j \in G_{i t}}{\operatorname{maximize}} & \sum_{j \in G_{i t}}\left(P_{t}\left(Q_{t}\right) q_{i t}^{j}-C_{i t}^{j}\left(q_{i t}^{j}\right)\right)+P_{t}\left(Q_{t}\right) q_{i t}^{M R}+\left(P_{i t}^{f}-P_{t}\left(Q_{t}\right)\right) q_{i t}^{f} & \\
\text { s.t. } & q_{i t}^{j} \leq q_{i t}^{j, M a x} & \forall j \in G_{i t} & : \lambda_{i t}^{j} \\
& q_{i t}^{j} \geq \psi_{i}^{j} q_{i t}^{j, M a x} & \forall j \in G_{i t} & : \mu_{i t}^{j}
\end{array}
$$

where $\lambda_{i t}^{j}$ and $\mu_{i t}^{j}$ represent the Lagrangian multipliers on the upper and lower bound constraints.

We consider two forms of market competition: perfect and Cournot competition. We define $\theta_{i}$ to represent the nature of firm competition. If $\theta_{i}=0$, then firm $i$ behaves as a price-taker. Alternatively, $\theta_{i}=1$ reflects Cournot competition. For each asset $j \in G_{i t}$, firm $i$ 's optimal output choice satisfies:

$$
P_{t}^{\prime}\left(Q_{t}\right) \theta_{i}\left[\left(\sum_{j \in G_{i}} q_{i t}^{j}\right)+q_{i t}^{M R}-q_{i t}^{f}\right]+P_{t}\left(Q_{t}\right)-C_{i t}^{j \prime}\left(q_{i t}^{j}\right)-\lambda_{i t}^{j}+\mu_{i t}^{j}=0 .
$$

where $C_{i t}^{j \prime}\left(q_{i t}^{j}\right)$ denotes the marginal cost of production from asset $j$. Under perfect competition $\left(\theta_{i}=0\right)$, firm $i$ behaves as a price-taker producing positive output from asset $j$ as long as $P_{t}\left(Q_{t}\right) \geq C_{i t}^{j \prime}\left(q_{i t}^{j}\right)$.

When a firm $i$ behaves as a strategic Cournot competitor $\left(\theta_{i}=1\right)$, its output decisions are affected by its forward position $q_{i t}^{f}$. A firm $i$ is a net seller (buyer) in the spot market if its aggregate production $\left(\sum_{j \in G_{i}} q_{i t}^{j}+q_{i t}^{M R}\right)$ exceeds (is below) its forward contracted output level $q_{i t}^{f}$. A firm only receives the spot market price $P_{t}\left(Q_{t}\right)$ for its output in excess of its forward contracted quantity. Therefore, when its forward commitment quantity $q_{i t}^{f}$ is large, it has less of an incentive to withhold output from the market to raise the spot market price. In fact, if a firm's forward position exceeds its aggregate production, the firm is a net buyer and so it produces more output than it would have if it behaved as a price-taker.

In our empirical application, we consider two equilibrium concepts. First, we analyze the perfectly competitive equilibrium where $\theta_{i}=0$ for all $i=1,2, \ldots, 6$. Second, we consider a Cournot-Nash equilibrium where five incumbents produce as Cournot Oligopolists and a competitive fringe behaves as a price-taker.

Our assumption of a Cournot model is somewhat at odds with the reality of electricity auctions, in which firms submit a schedule of price-quantity pairs indicating the price at which they are willing to supply a certain quantity. An alternative approach would be to attempt to more directly capture the multi-unit auction nature of electricity markets through Supply Function Equilibria (SFE) (Klemperer and Meyer, 1989). The authors demonstrate that market power is bounded above by the Cournot outcome and from below by homogeneous products Bertrand, although the authors do not account for firms' forward commitments.

Our decision to focus on a Cournot model is based on several considerations. First, as noted by Borenstein and Bushnell (1999) and Baldick et al. (2004), a key advantage of the SFE approach is in situations in which firms submit offers that apply for an extended period of time (such as a day) where a wide range of demand is expected. In contrast, in Alberta's electricity market firms submit offer curves for each hour of the day, and can update them up to two hours in advance. Second, a Cournot approach is preferred for computational reasons. As a result, Cournot models have been used extensively to model oligopoly behavior in electricity markets (Ventosa et al., 2005). Third, Bushnell et al. (2008) demonstrate using data for PJM, New England, and California that a Cournot model fits observed market outcomes well when firms' forward commitments are taken into account (as we do in our analysis). 


\section{Empirical Methodology}

In this section, we discuss the data, estimation of asset-level marginal costs and the residual demand function faced by suppliers in Alberta, and the empirical methodology used to estimate the perfectly competitive and Cournot-Nash equilibrium outcomes for each hour in our sample.

\subsection{Data}

We use publicly available data from the Alberta Electric System Operator (AESO) from January 1, 2014 to December 31, 2015. This data set includes hourly observed price and quantity offers for all firms in Alberta, unit-level production, import supply, transmission capacity limits, market-level demand, and the identify and ownership of generation assets. We use hourly natural gas and coal prices from Alberta's Natural Gas Exchange (NGX) and Wyoming's Powder River Basin to compute fuel input costs, respectively. We obtained hourly weather data for British Columbia (BC), Alberta, and Saskatchewan (SK) from Environment Canada: Weather Information. Our sample includes 17,520 hours. Table 3 provides summary statistics for several key market characteristics in our sample.

Table 3: Market-Level Summary Statistics

\begin{tabular}{lccccccc}
\hline & Units & Mean & Std. Dev. & Min & Median & Max & $\mathrm{N}$ \\
\hline Quantity Demanded & MWh & 8,277 & 703 & 6,250 & 8,307 & 10,300 & 17,520 \\
System Marginal Price & $\$$ MWh & 41.31 & 100.55 & 0.00 & 22.75 & 999.99 & 17,520 \\
Imports & MWh & 177 & 207 & 0.00 & 100 & 1,230 & 17,520 \\
\hline
\end{tabular}

\subsection{Marginal Cost Functions}

We estimate the marginal cost of fossil-fired thermal generation units using hourly natural gas $(N G)$ and coal $(C)$ price data $\left(p_{t}^{N G}, p_{t}^{C}\right)$, unit-specific thermal efficiencies measured by an asset's heat-rate $\left(H R_{i}^{j}\right)$, variable operating and maintenance $(\mathrm{O} \& \mathrm{M})$ costs, and environmental compliance costs $\left(e_{i t}^{j}\right)$. A unit $j$ 's constant marginal cost $c_{i t}^{j}$ up to its maximum capacity equals the summation of its fuel $\operatorname{costs}\left(p_{t}^{l} \times H R_{i}^{j}\right.$ for $l \in\{N G, C\}$ ), variable O\&M costs, and the marginal environmental compliance costs. See Appendix A for details on data sources.

In our estimation of marginal costs, to account for generation unit outages, we adjust the maximum name-plate capacity $c_{i p}^{j}$ of each fossil-fired unit by the probability of a forced outages, derated to account for partial unit availability $\left(d f o f_{i}^{j}\right){ }^{19}$ The available capacity of unit $j$ equals $q_{i t}^{j, \text { Max }}=\left(1-d f o f_{i}^{j}\right) * c a p_{i}^{j}$. Coal generation units in our sample have a minimum stable generation (MSG) level below which they cannot maintain reliable combustion conditions. We assume that the MSG equals $\psi_{i}^{j}=35 \%$ for each coal unit. ${ }^{20}$ In the event that a unit was unavailable for an entire month, we suppose that this is a long-term outage that can be considered exogenous, and exclude this unit for the month.

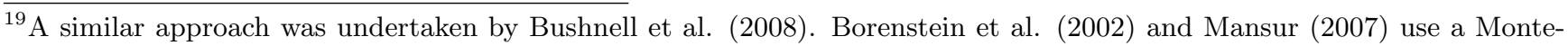
Carlo approach to simulate the stochastic process associated with unit availability. This approach is numerically intractable in our analysis.

${ }^{20}$ This is a conservative estimate on the MSG in Alberta (see Brown and Eckert (2017) for a related discussion) but is consistent with the ranges used in the literature. For example, Neuhoff et al. (2013) assume that MSG equals $38 \%$ in an analysis of European markets.
} 
We model three environmental compliance costs scenarios for fossil-fired generation units in Alberta:

1. SGER15 is the baseline SGER in effect in 2014 and 2015. Under this regulation, large emitting generation units are required to reduce their emission intensities $\left(E I_{i}^{j}\right)$ below a facility-level baseline by $12 \%$. Emission intensities in excess of $88 \%$ of their facility-level baseline are required to pay a compliance cost of $\$ 15$ per tonne of $\mathrm{CO}_{2}$ e. For each asset $j \in G_{i t}$, the marginal environmental costs on large emitting facilities $e_{i t}^{j}=15 \times 0.12 \times E I_{i}^{j}$.

2. SGER17 is the 2017 carbon pricing regulations. Under the updated SGER regulation, large generation units are required to reduce their baseline emission intensity by $20 \%$. Emission intensity in excess of $80 \%$ of their facility-level baseline emission intensity are required to pay a compliance cost of $\$ 30$ per tonne of $\mathrm{CO}_{2} \mathrm{e}$. For each asset $j \in G_{i t}$, the marginal environmental costs on large emitting facilities $e_{i t}^{j}=30 \times 0.20 \times E I_{i}^{j}$.

3. CCR is expected to be implemented in 2018. All fossil-fired assets are required to pay $\$ 30$ per tonne of $\mathrm{CO}_{2} \mathrm{e}$ on all emissions. Each unit receives an output-based subsidy equal to $30 \times \bar{I}$ per MWh, where $\bar{I}$ reflects the emissions intensity of an efficient natural gas unit. Discussions with industry suggest an intensity target $\bar{I}=0.375$. For each asset $j \in G_{i t}$, the marginal environmental costs on natural gas and coal assets $e_{i t}^{j}=30\left[E I_{i}^{j}-\bar{I}\right] \cdot{ }^{21}$

A sizable portion of generation in Alberta is arising from cogeneration and wind turbines. Cogeneration facilities generate heat and electricity as a by-product of an on-site industrial process. All electricity that is not consumed on-site is sold to the wholesale market. We assume that output from wind and cogeneration facilities have a marginal cost equal to zero. These assets systematically submit offers equal to zero into the wholesale market. For a limited number of hours, several natural gas based cogeneration units submit non-zero offers into the spot market and produce electricity beyond their on-site needs. For these units, we compute the marginal cost as we would with a traditional natural gas fired asset.

There are several small hydroelectric units in Alberta. Because hydro units can store their generation potential, marginal costs represent the opportunity cost of using the energy at some other time. Similar to Borenstein et al. (2002), Mansur (2007), and Brown and Olmstead (2017), we assume that the output generated by hydro units is identical to the amount that would be produced by a price-taking firm. ${ }^{22}$

\subsection{Import Supply and Residual Demand}

We estimate the hourly supply of electricity from neighboring provinces British Columbia (BC) and Saskatchewan $(\mathrm{SK}){ }^{23}$ Firms in neighboring provinces choose to supply imports to Alberta based on relative prices. For each hour $t$, we estimate imports from province $j$ as a linear-log function of price $p_{t}$ :

${ }^{21}$ If $E I_{i}^{j}<\bar{I}$, an asset's marginal environmental compliance costs is negative and the asset is compensated per MWh.

${ }^{22}$ We apply the observed output from hydro generation for each hour and analyze the amount of non-hydro production necessary to meet hourly demand net of hydro generation. The biases associated with this approach are limited in the Alberta context because hydro assets are systematically not marginal generators. Further, hydro represents approximately $2 \%$ of annual production in Alberta (see Table 1).

${ }^{23}$ There is a small transmission intertie with Montana. However, due to market reliability regulations within Alberta, the connection with Montana added minimal transmission capacity to the system (MSA, 2012). We include the limited imports from Montana with the BC import supply function. 


$$
\begin{aligned}
Q_{j t}^{I M}=\beta_{0 j} & +\beta_{1 j} \ln \left(p_{t}\right)+\beta_{2 j} \text { Weekday }_{\mathrm{t}}+\beta_{3 j} \text { Holiday }_{\mathrm{t}}+\beta_{4 j} \text { Year }_{2015}+\beta_{5 j} \text { ImportCap }_{\mathrm{jt}} \\
& +\alpha_{j} \mathrm{~h}\left(\text { Temp }_{\mathrm{jt}}\right)+\sum_{h=1}^{24} \omega_{h j} \text { Hour }_{\mathrm{ht}}+\sum_{m=1}^{12} \gamma_{m j} \text { Month }_{\mathrm{mt}}+\epsilon_{j t} \quad \forall j \in\{B C, S K\}
\end{aligned}
$$

where $\mathrm{h}\left(\mathrm{Temp}_{\mathrm{jt}}\right)$ is a nonlinear function of temperature variables in neighboring province $j$, ImportCap $\mathrm{p}_{\mathrm{jt}}$ is hourly transmission import capacity, Weekday $y_{t}$ is an indicator function for weekday, Holidayt , Hour $_{\mathrm{ht}}$, Month $_{\mathrm{mt}}$, and Year $_{2015 \mathrm{j}}$ are indicator variables for each provincial holiday in Alberta, hour, month, and year in our sample, respectively. ${ }^{24}$ The calender fixed effects (hourly, weekday, month, year) are included to control for systematic input supply shocks and demand variation in each province that impacts relative prices. Import capacity limits control for hourly variation in intertie capacities. Temperatures in neighboring provinces control for changes in relative demand conditions.

Electricity prices in Alberta are endogenous to the degree of imports. Failure to account for this endogeneity results in attenuation bias on the price coefficient. Similar to Mansur (2007) and Bushnell et al. (2008), we estimate (6) for each neighboring province using two-stage least squares (2SLS) and instrument price using day-ahead hourly demand forecasts. This serves as a valid instrument because wholesale electricity demand is perfectly price-inelastic in Alberta. The majority of consumers face fixed retail rates that vary at most monthly. Further, forecasted demand in Alberta only impacts imports through its impact on the market price.

Table A1 in the Appendix provides detailed results of the import supply functions for both provinces. ${ }^{25}$ The import supply functions yield average price-elasticities of import supply equal to 1.47 and 0.34 for BC and SK, respectively.

Having estimated import supply from neighboring provinces, the price-elastic residual demand $Q_{t}\left(p_{t}\right)$ served by suppliers in Alberta equals price-inelastic demand in Alberta $\bar{Q}_{t}$ minus the price-responsive supply of electricity from neighboring provinces $\sum_{j \in\{S K, B C\}} \widehat{Q}_{j t}^{I M}\left(p_{t}\right)$. The average price elasticity of residual demand equals -0.038 . This is similar to estimated residual demand price-elasticities in numerous electricity markets in the United States (Bushnell et al., 2008). We invert the residual demand function to establish the inverse residual demand function $P_{t}\left(Q_{t}\right)$ faced by suppliers within Alberta:

$$
Q_{t}\left(p_{t}\right)=\bar{Q}_{t}-\sum_{j \in\{B C, S K\}} \widehat{Q}_{j t}^{I M}\left(p_{t}\right)=\widehat{\alpha}_{t}-\widehat{\gamma} \ln \left(p_{t}\right) \Rightarrow P_{t}\left(Q_{t}\right)=e^{\frac{1}{\widehat{\gamma}}\left(\widehat{\alpha}_{t}-Q_{t}\right)} .
$$

\subsection{Estimation Method}

Having estimated unit-level marginal cost and an hourly residual demand function, we discuss the equilibrium conditions and estimation methodology to characterize the hourly perfectly competitive and Cournot-Nash equilibria. For each firm, we treat observed electricity output that has zero marginal

\footnotetext{
${ }^{24}$ The hourly temperature variables are modeled as quadratics of heating degrees (average degrees below $18.33^{\circ}$ Celsius $\left(65^{\circ}\right.$ $\mathrm{F})$ ) and cooling degrees (average degrees above $18.33^{\circ}$ Celsius $\left(65^{\circ} \mathrm{F}\right)$ ). The cities considered in BC and $\mathrm{SK}$ are the major load centers Vancouver and Saskatoon, respectively. The results of our analysis are robust to higher degree polynomials and alternative load centers in each province.

${ }^{25}$ We estimate the model using 2SLS with heteroskedastic robust standard errors and 24 lags. For both the BC and SK import supply functions, the Kleibergen-Paap F-Statistic for the BC and SK estimations are 184.26 and 154.55, respectively. Both strongly reject the null hypothesis that our instrument is weak. For additional details on the import supply function estimation and functional form specification selection, see Appendix B.
} 
cost of production (i.e., wind and cogeneration) as must-run $\left(q_{i t}^{M R}\right) \cdot{ }^{26}$

Using (4) and (5), for each equilibrium concept $\theta_{i} \in\{0,1\}$, the hourly equilibrium outcome can be characterized by the following nonlinear mixed complementarity program (MCP):

$$
\begin{gathered}
P_{t}^{\prime}\left(Q_{t}\right) \theta_{i}\left[\left(\sum_{j \in G_{i}} q_{i t}^{j}\right)+q_{i t}^{M R}-q_{i t}^{f}\right]+P_{t}\left(Q_{t}\right)-C_{i t}^{j \prime}\left(q_{i t}^{j}\right)-\lambda_{i t}^{j}+\mu_{i t}^{j}=0 ; \\
q_{i t}^{j} \leq q_{i t}^{j, M a x} \quad \perp \quad \lambda_{i t}^{j} \geq 0 ; \quad \text { and } \\
q_{i t}^{j} \geq \psi_{i}^{j} q_{i t}^{j, M a x} \quad \perp \quad \mu_{i t}^{j} \geq 0
\end{gathered}
$$

for all $j \in G_{i t}$ and $i=1,2,3,4,5,6$, where $\perp$ indicates complementarity. For each period $t$, simultaneously solving for the dual and primal variables $\left\{q_{i t}^{j}, \lambda_{i t}^{j}, \mu_{i t}^{j}\right\}$ for all $i$ and $j$ yields an equilibrium that characterizes each firm's asset-level production decisions and the wholesale market price.

We consider two equilibrium concepts: (i) perfect competition where all firms behave as price-takers $\left(\theta_{i}=0\right.$ for all $\left.i=1,2, . ., 6\right)$ and (ii) Cournot-Nash competition where five large incumbents behave as Oligopolists $\left(\theta_{i}=1\right.$ for all $\left.i=1,2, . ., 5\right)$ and a fringe of small producers behave as price-takers $\left(\theta_{6}=0\right) .{ }^{27}$ For both cases, we implement this large-scale MCP using GAMS software and the PATH algorithm (Ferris and Munson, 2000) on the NEOS numerical optimization server (Czyzyk et al., 1998).

In the Cournot-Nash equilibrium, the strategic firms' unit-level production decisions depend on their forward (retail) commitments $q_{i t}^{f}$. We calibrate firm-specific peak and off-peak monthly forward positions to minimize the difference between the model predicted equilibrium market price under the baseline status quo SGER15 carbon pricing setting and observed market prices. ${ }^{28}$ It is important to note that the baseline SGER15 policy was in place in 2014 and 2015. For both the perfect and imperfect competition settings, we model three carbon pricing scenarios that impact asset-level marginal cost: the baseline SGER15, the updated SGER17, and the CCR policy.

\section{Results}

We begin by comparing the predictions from our calibrated baseline SGER15 model with observed prices and output. We then discuss the simulated effects of the two carbon pricing policy changes under the assumption of perfect competition. Under perfect competition, the only impacts of the change in carbon pricing policies is the adjustment in marginal costs and the change in the merit order of the generation assets. We then outline the predicted changes under Cournot competition, which reflects changes in marginal costs, the merit order of assets, and firms' strategic behaviour. Finally, we provide a brief discussion of the predicted effects on unit and firm-level profitability for both market structures.

\footnotetext{
${ }^{26}$ Wind generation is exogenous. Cogeneration production decisions are made to serve on-site electricity demand and any excess electricity is sold to the wholesale market at a price of zero.

${ }^{27}$ The system of equations in (8) is a square MCP with an equal number of variables and complementarity conditions. Because each firm's profit functions are globally pseudo concave and strictly concave locally at the solution to (8), the solution to this MCP constitutes a unique perfectly competitive equilibrium if $\theta_{i}=0$ for all $i=1,2, \ldots, 6$ and a unique Cournot-Nash equilibrium with a competitive fringe when $\theta_{i}=1$ for all $i=1,2, \ldots, 5$ and $\theta_{6}=0$ (Kolstad and Mathiesen, 1991).

${ }^{28}$ In Alberta, the majority of forward contracts are monthly peak and off-peak contracts (MSA, 2010).
} 


\subsection{Baseline Model}

We compare the observed market prices and output to those estimated under the Cournot and perfectly competitive market structures for the baseline SGER15 carbon pricing policy. Table 4 compares observed average prices and output to those estimated under both market structures for the SGER15 policy.

\begin{tabular}{cccccc}
\multicolumn{2}{c}{ Table 4: Observed and Predicted Average Prices and Output, SGER15 } \\
\cline { 2 - 3 } \cline { 5 - 6 } \cline { 5 - 6 } Observed & \multicolumn{2}{c}{ Peak Hours } & & \multicolumn{2}{c}{ Off-Peak Hours } \\
\cline { 2 - 3 } & $\$ 56.50$ & Quantity & & Price & Quantity \\
\hline \multirow{2}{*}{ Cournot-Nash } & $(133.61)$ & $(466)$ & & $\$ 27.95$ & 7,750 \\
& $\$ 57.75$ & 8,411 & & $\$ 29.44$ & 7,717 \\
Perfect Competition & $(86.36)$ & $(478)$ & & $(28.95)$ & $(576)$ \\
& $\$ 22.80$ & 8,610 & & $\$ 18.76$ & 7,818 \\
& $(11.10)$ & $(471)$ & & $(5.79)$ & $(607)$
\end{tabular}

Notes: Prices are given in \$/MWh and Quantity in MWhs. The associated standard deviations are given in parentheses.

Not suprisingly, the Cournot-Nash prices are close to observed prices in both peak and off peak hours, as the baseline Cournot model is calibrated by choosing firm-specific peak and off-peak forward contract positions to fit observed prices. In both peak and off-peak hours, average observed prices are slightly lower than the Cournot-Nash predictions but significantly higher than the average predicted perfectly competitive prices. Likewise, average Cournot quantities are closer than the perfectly competitive quantities to observed quantities. The variance in predicted prices (quantities) is lower (higher) than that in the observed outcomes, but again the Cournot-Nash better matched the observed price variance. ${ }^{29}$

In addition to differences in average predicted prices and output, the estimated domestic emissions and generation mix differ between the perfectly competitive and Cournot models. Table 5 presents the average hourly estimated domestic emissions, the emissions intensity, generation by coal, and the percentage of predicted output from coal units for the baseline SGER15 model. Similar to the findings in Mansur (2007), average hourly emissions are lower under Cournot competition as the relatively dirty large firms withhold output to elevate market prices. This withheld production is displaced by higher cost (lower emission) natural gas units operated by the fringe. As a result, for each market structure considered, the subsequent simulations that analyze the emissions reduction effects of Alberta's carbon pricing policies are in reference to a different baseline level of emissions.

Table 5: Average Predicted Emissions, Emissions Intensity, and Coal Generation

\begin{tabular}{ccccc}
\hline & Emissions & Emissions Intensity & Coal & Percentage Coal \\
\hline Perfect Competition & 4,870 & 0.59 & 5,102 & 62 \\
Cournot-Nash & 4,516 & 0.56 & 4,596 & 57 \\
Observed & 4,468 & 0.55 & 4,445 & 55 \\
\hline
\end{tabular}

Notes: Emissions are tonnes of $\mathrm{CO} 2 \mathrm{e}\left(\mathrm{tCO}_{2} \mathrm{e}\right)$, emissions intensity is measured in tonnes/MWh, coal production in MWh, and percentage coal in \%.

\footnotetext{
${ }^{29}$ Brown and Eckert (2016) and Brown and Olmstead (2017) provide additional evidence that observed behavior deviates from perfect competition in Alberta.
} 
Finally, our Cournot model is calibrated to the data through the choice of monthly firm-specific peak and off-peak forward positions. Hence, it is important consider the reasonableness of the estimated forward positions. Over the sample period, our average estimated forward positions range across firms from $79 \%$ to $89 \%$ in peak hours and from $86 \%$ to $94 \%$ in off-peak hours. These forward positions are consistent with those obtained from studies which have either made use of available data on forward contracting or have estimated forward positions using observed behaviour and a structural assumption on the nature of competition (Hortascu and Puller, 2008; Bushnell et al., 2008; Reguant, 2014; Brown and Eckert, 2016). Forward positions from these analyses, as a percentage of output, have ranged from $73 \%$ to $103 \%$.

\subsection{Perfect Competition}

Table 6 presents the average price, output, and domestic emissions under the three scenarios as well as the percentage change from each phase of carbon pricing by year. While doubling the carbon price in SGER17 increases price and reduces output and emissions, the effect of changing the allocation rule under CCR has a substantially larger effect on prices and emissions. CCR greatly increases the marginal costs of coal generators and leads to a high degree of market-level fuel switching of production from coal to gas assets. Overall, CCR reduces average emissions by more than four times as much as SGER17. As discussed in more detail below, this effect is magnified in 2015 because of the entry of a large highly efficient natural gas facility which causes a higher degree of fuel substitution between coal and gas production. The limited reduction in output reflects a reduction in domestic output that is being displaced by imports from neighboring provinces because hourly electricity demand is largely perfectly price-inelastic. ${ }^{30}$

Table 6: Predicted Average Outcomes under Perfect Competition by Year

\begin{tabular}{cccccccc}
\hline Year & Scenario & Price & $\% \Delta$ Price & Market Output & $\% \Delta$ Output & Emissions & $\% \Delta$ Emissions \\
\hline \multirow{2}{*}{2014} & SGER15 & 22.67 & & 8,249 & & 5,052 & \\
& SGER17 & 25.99 & 14.6 & 8,198 & -0.6 & 5,001 & -1.0 \\
& CCR & 34.98 & 34.6 & 8,096 & -1.3 & 4,618 & -7.7 \\
\hline \multirow{2}{*}{2015} & SGER15 & 18.71 & & 8,100 & & 4,689 & \\
& SGER17 & 22.13 & 18.3 & 8,047 & -0.7 & 4,448 & -5.1 \\
& CCR & 31.59 & 42.8 & 7,938 & -1.4 & 3,519 & -20.9 \\
\hline
\end{tabular}

Notes: Price, output, and emissions are given in $\$ / \mathrm{MWh}, \mathrm{MWh}$, and $\mathrm{tCO}_{2} \mathrm{e}$. The $\% \Delta$ represents the percentage change from the previous phase of the carbon pricing policy.

To better understand the role of cost increases and the marginal technology, Table 7 presents the predicted changes in market outcomes by demand quartiles. The price and emissions effects are lowest for the highest demand hours. In these hours, coal is generally fully dispatched and the marginal technology is natural gas. As a result, there is a limited increase in the marginal cost of the natural gas unit(s) on the margin, and there is a limited degree of fuel substitution because prices are sufficiently high that coal will be fully dispatched both before and after the policy changes.

In the low to mid demand hours, the role of demand on the price pass-through and emissions reduction is complex. The price-pass through is larger because coal is often the marginal technology. Further, larger emissions reductions occur during these hours because of the substitution of production from coal to gas

\footnotetext{
${ }^{30}$ Imports primarily come from the neighboring province of British Columbia whose production reflects largely hydroelectric generation. As a result, a reduction in output is largely met by production from a cleaner technology.
} 
Table 7: Price and Emissions Changes Under Perfect Competition by Quartiles of Demand

\begin{tabular}{|c|c|c|c|c|c|c|c|c|}
\hline \multirow[b]{2}{*}{ Scenario } & \multicolumn{4}{|c|}{ Change in Average Price } & \multicolumn{4}{|c|}{ Change in Average Emissions } \\
\hline & Q1 & Q2 & Q3 & Q4 & Q1 & Q2 & Q3 & Q4 \\
\hline SGER17 & 3.93 & 3.82 & 3.39 & 2.38 & 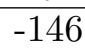 & -171 & -175 & -111 \\
\hline CCR & 9.30 & 10.58 & 10.29 & 6.71 & -712 & -703 & -664 & -543 \\
\hline
\end{tabular}

Notes: Price changes are given in $\$ / M W h$ and emissions changes in $\mathrm{tCO}_{2} \mathrm{e}$. Changes in emissions and prices represent the absolute change from the previous phase of the carbon pricing policy.

generation. Below, we provide a more detailed analysis of the relationship between demand and price pass-through and emissions effects. In particular, we illustrate that these effects were altered drastically by the entry of a large (860 MW) low cost natural gas asset at the end of 2014. For illustrative purposes, in the subsequent discussion we focus on the price pass-through effects of the change in the carbon price from SGER15 to CCR.

Figure 2: Marginal Costs and Residual Demand, Jan. 14, 2014, Hour 2 and Hour 8

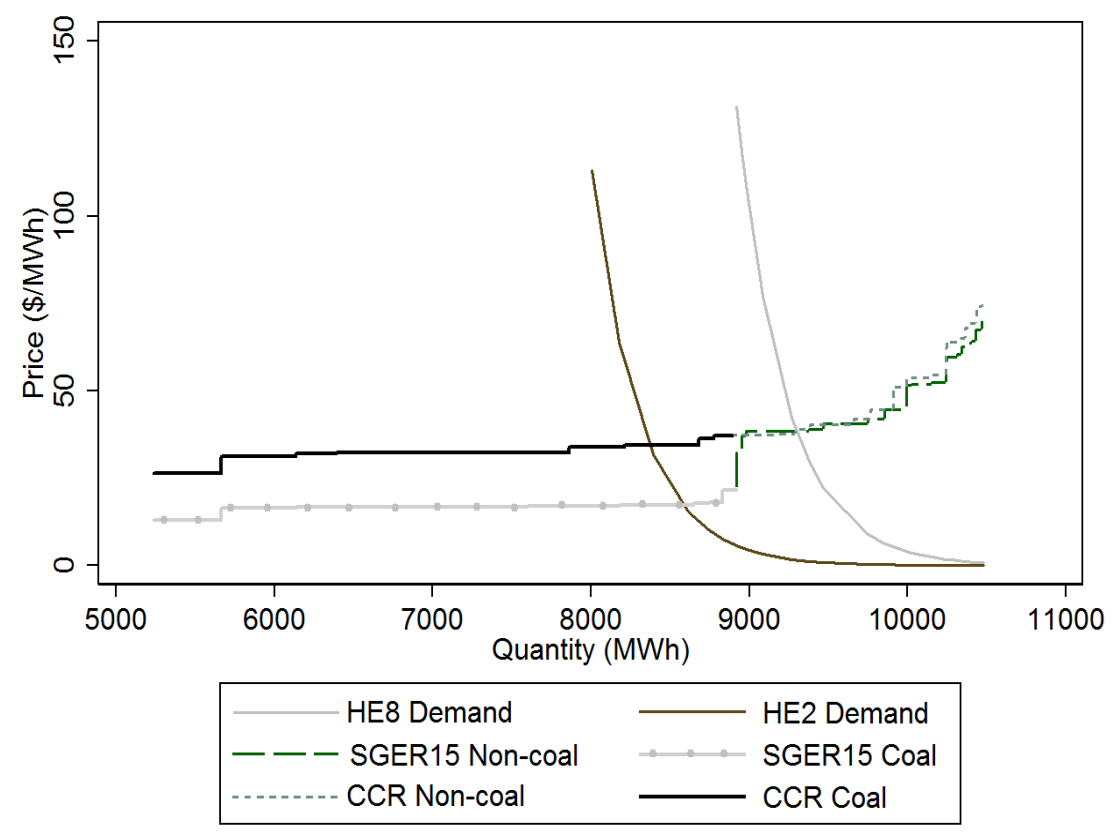

Figure 2 presents the short-run marginal cost curves under SGER15 and CCR for a representative day in early 2014, along with estimated residual demand curves for two hours (1:00 - 2:00 AM and 7:00 - 8:00 AM). On each short-run supply curve, the sections corresponding to coal and natural gas generation units are highlighted. The transition from SGER15 to CCR essentially amounted to an upward shift in the coal portion of the supply curve; the marginal costs of natural gas units were largely unchanged. Further, the sequence of coal and natural gas assets in the merit order exhibits limited changes. ${ }^{31}$

The price effect of the transition from SGER15 to CCR in both hours is simply the increase in the marginal cost of the marginal technology. In the low demand hour, since the marginal technology both before and after the policy change is coal, the price effect is large $(\$ 17.28)$. Alternatively, in the high demand hour, the price increases by only $\$ 0.57$. The effect on emissions is likewise minor in both hours,

\footnotetext{
${ }^{31}$ There is a single inefficient coal unit whose marginal cost now exceeds that of the most efficient natural gas assets.
} 
since there is little change to the merit order and limited fuel substitution between coal and gas generation; emissions decrease by only 108 and $221 \mathrm{tCO}_{2}$ e from 7:00 - 8:00 AM and 1:00 - 2:00 AM, respectively.

Figure 3: Marginal Costs, October 18, 2015, Hour 18

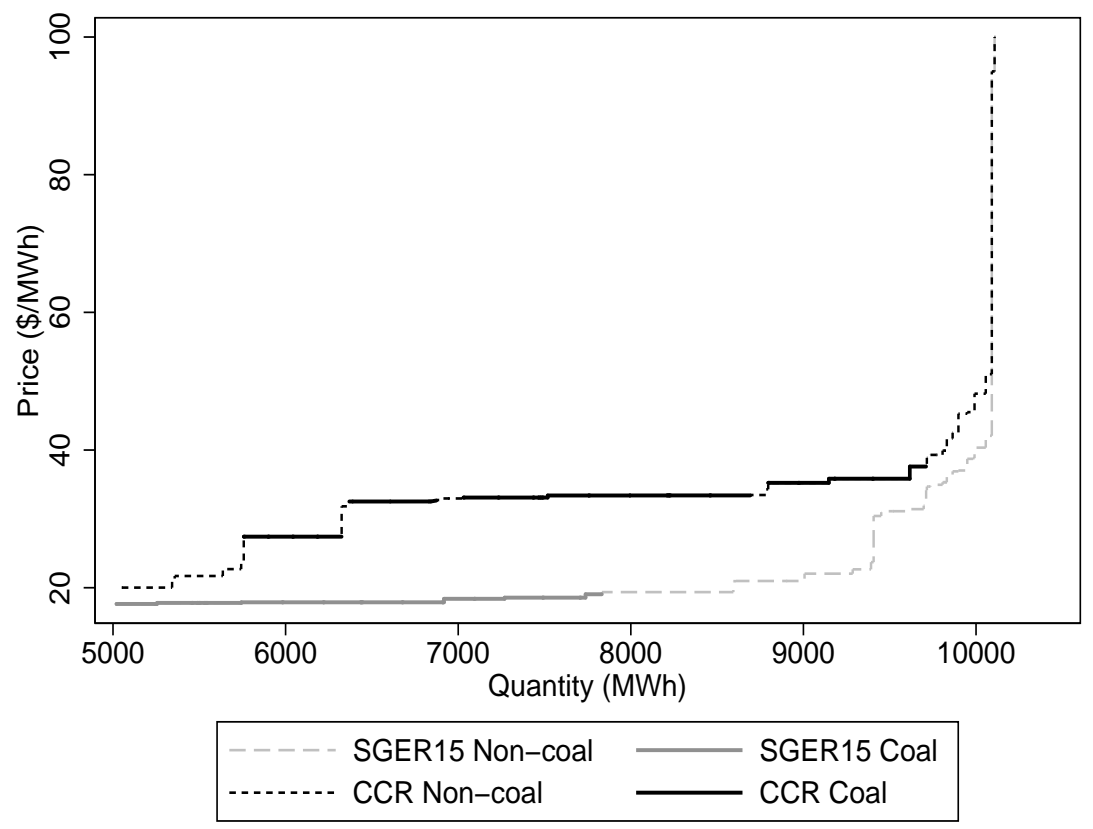

In contrast, Figure 3 illustrates the competitive supply curves under SGER15 and CCR for an hour in 2015, in which there has been a large increase in the availability of low cost natural gas generation. As can be seen in the figure, the shift from SGER15 to CCR results in a change in the positions of coal and natural gas in the merit order, with a large quantity of low cost natural gas capacity moving below coal. As a result of this fuel substitution, the price effect of the switch from SGER15 to CCR in low demand hours (e.g., demand less than 5,700 MWh) will be much lower than the increase in the marginal cost of coal generation. For the same reason, the effect on emissions will be greater.

The above discussion suggests that the price pass-through and emissions effects depend critically on the level of market demand, and also the presence of low cost natural gas. To generalize these arguments, we plot hourly price effects against SGER15 market output for each of 2014 and 2015.

Figure 4 presents the hourly price effect of moving from the baseline SGER15 to CCR in 2014 by demand levels, highlighting which generation technology was marginal under SGER15. The price effects can be roughly categorized into three regions. In Region A, representing $70 \%$ of hours, a large price increase results from the marginal technology being a coal generation unit of similar efficiency both before and after the implementation of the CCR policy. Region B, reflecting approximately $20 \%$ of hours, consists of hours in which the the marginal technology both before and after the implementation of CCR is a natural gas unit, leading to a price effect that was low or negative. Both of these regions have small changes in emissions because there is limited substitution of production between coal and gas assets. The average hourly predicted emissions reductions are between 190 and 215 tonnes.

Finally, in the $10 \%$ of hours captured by Region C, under SGER15 residual demand intersects the industry marginal cost curve near the shelf where lower cost coal units are capacity constrained and higher cost gas units begin to be dispatched (e.g., demand levels 8,500 - 9,250 MWhs in Figure 2). As a result, 
Figure 4: Price Change By SGER15 Output, Perfect Competition, 2014

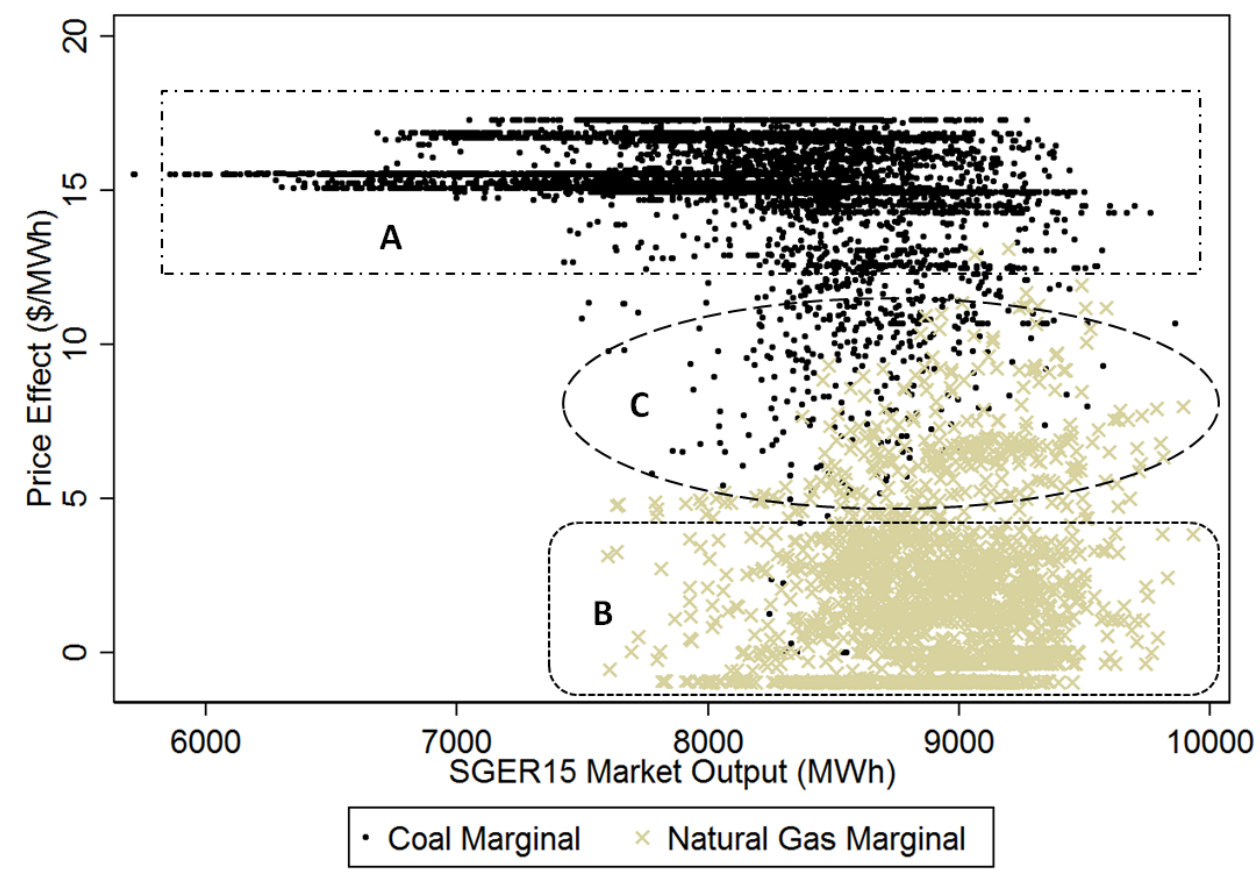

the price effect reflects the relative change in marginal cost of the assets on the margin before and after the implementation of CCR. For example, a price effect in the range of $\$ 12$ corresponds to hours in which the marginal unit switches from coal under under SGER15 to natural gas under CCR. As a result, the price pass-through does not represent the total change in the marginal cost of the coal unit that was marginal initially under SGER15. The change in emissions due to the CCR policy is largest in this region because of the higher degree of fuel substitution. For certain hours, we observe emission reductions as high as 1,000 tonnes in this demand region.

A substantially different relationship is observed for 2015 due in large part because of the entry of a large efficient natural gas unit. Figure 5 illustrates the hourly price effect of moving from the baseline SGER15 to CCR in 2015 by demand levels, highlighting which generation technology was marginal under SGER15. Similar to 2014, Region A represents the majority of hours (55\%) and systematically reflects hours where the marginal technology is a coal unit with similar efficiency both before and after the CCR implementation. ${ }^{32}$ However, unlike 2014, region B no longer exists. The higher cost natural gas units that were marginal at higher demand levels in 2014 are no longer dispatched in 2015 because of the entry of the large low-cost natural gas asset.

Region C1 and C2 represents hours under SGER15 where residual demand intersects the industry marginal cost curve near the shelf where lower cost coal is capacity constrained and higher cost gas begins to be dispatched. Regions C1 and C2 represent $20 \%$ and 25\% of the hours in 2015, respectively. Similar to region $\mathrm{C}$ in 2014, the price effect in regions $\mathrm{C} 1$ and $\mathrm{C} 2$ reflect the relative change in marginal cost of the assets on the margin before and after the implementation of CCR. More specifically, region $\mathrm{C} 1$ reflects hours where a relatively inefficient coal unit was marginal under SGER15 and a move to CCR causes this

\footnotetext{
${ }^{32}$ Unlike Figure 4, there are hours in Region A where a gas asset was the marginal asset under SGER15. The high observed price effects are arising in these hours because this gas asset had similar marginal cost as the coal assets that are being fully dispatched under SGER15. Under the CCR policy, this natural gas asset is fully dispatched and coal becomes the marginal technology. As a result, the price effects reflects the change in the marginal cost of the now marginal coal assets.
} 
Figure 5: Price Change By SGER15 Output, Perfect Competition, 2015

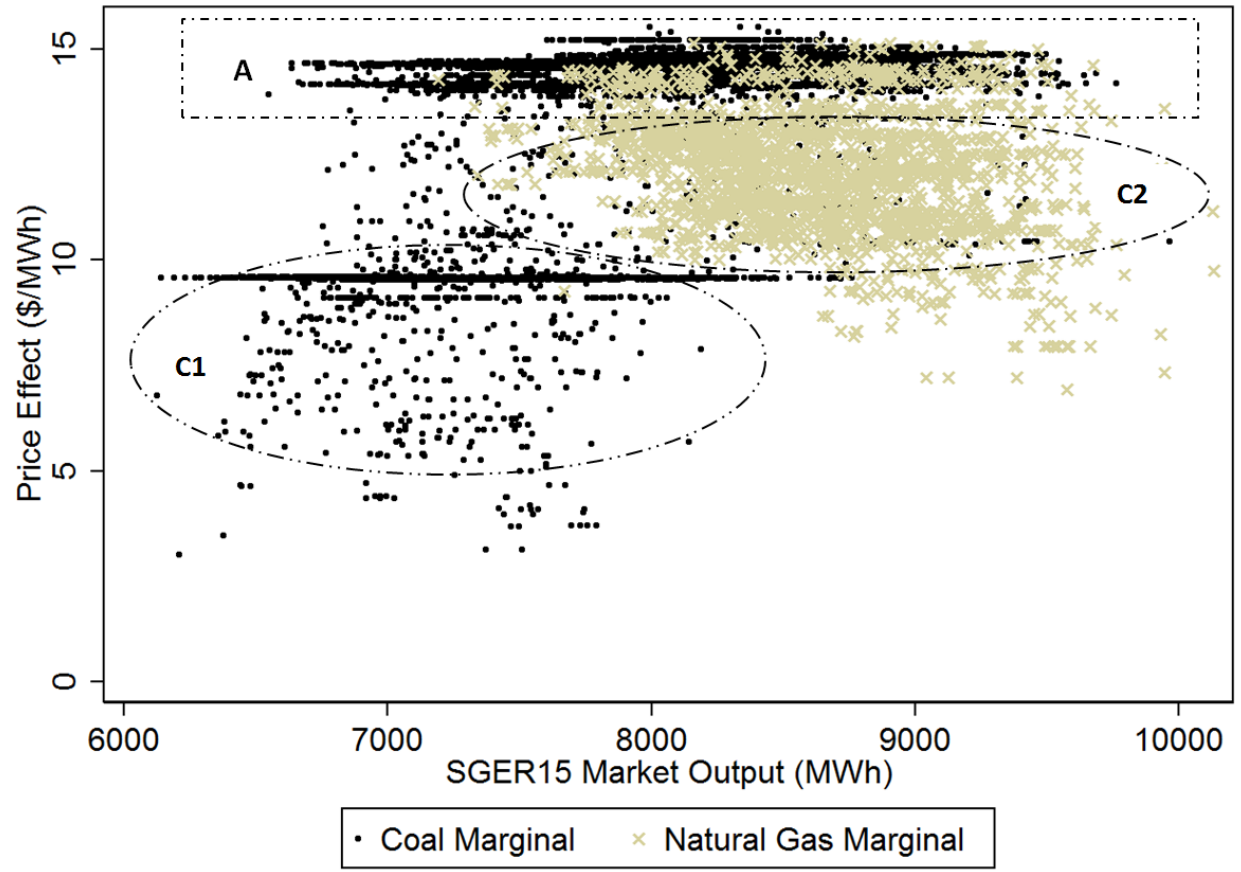

unit to no longer be dispatched because the new efficient natural gas unit is now lower cost and fully dispatched. The marginal unit under CCR reflects a more efficient (lower cost) coal unit. ${ }^{33}$ Alternatively, region $\mathrm{C} 2$ represents hours where an efficient natural gas unit is on the margin under SGER15 and the coal units are being fully dispatched. Then, under the CCR, natural gas units displace coal production and coal becomes the unit on the margin.

In both 2014 and 2015, the regions C and C1 and C2 represent hours where the marginal unit systematically differs as we move from SGER15 to the CCR policy. The asymmetric impact of the output subsidy on the marginal cost of coal units and the addition of a large efficient natural gas unit causes more fuel substitution to occur in this region in 2015. In fact, for any quartile of demand, the degree of fuel switching is greater in 2015. The average proportion of the reduction in coal output that is offset by natural gas production is greater than $90 \%$ for all quartiles in 2015 .

\subsection{Cournot Competition}

Table 8 shows the predicted changes in price, output, and emissions under Cournot competition. Recall, that these reductions are relative to a higher price and lower output and emissions than the reductions under perfect competition. As in the case of perfect competition, the change in the output-based subsidy has a substantially larger impact on the price and emissions than does the doubling of the carbon price. Further, similar to perfect competition, the emissions reducing effect of the CCR policy change is larger in 2015 compared to 2014. Although, this effect is somewhat dampened under Cournot competition.

Table 9 provides the price and emissions changes by quartile of demand. Again, CCR generates substantially larger price increases and emissions reductions at all levels of demand. In contrast to the

\footnotetext{
${ }^{33}$ The mass of price effects observed between $\$ 9$ and $\$ 10$ represent hours where a relatively inefficient coal asset was marginal under SGER15. Under CCR, a relatively more efficient coal unit is setting the market price. As a result, the price effect represents the relative change in marginal cost of these two coal assets.
} 
Table 8: Predicted Average Outcomes under Cournot Competition by Year

\begin{tabular}{cccccccc}
\hline Year & Scenario & Price & $\% \Delta$ Price & Market Output & $\% \Delta$ Output & Emissions & $\% \Delta$ Emissions \\
\hline \multirow{2}{*}{2014} & SGER15 & 51.79 & & 8,068 & & 4,749 & \\
& SGER17 & 55.94 & 8.0 & 8,034 & -0.4 & 4,693 & -1.2 \\
& CCR & 66.21 & 18.4 & 7,968 & -0.8 & 4,419 & -5.8 \\
\hline \multirow{2}{*}{2015} & SGER15 & 34.05 & & 7,986 & & 4,283 & \\
& SGER17 & 37.52 & 10.2 & 7,949 & -0.5 & 4,148 & -3.1 \\
& CCR & 45.42 & 21.1 & 7,883 & -0.8 & 3,583 & -13.6 \\
\hline
\end{tabular}

Notes: Price, output, and emissions are given in $\$ / M W h, \mathrm{MWh}$, and $\mathrm{tCO}_{2} \mathrm{e}$. The $\% \Delta$ represents the percentage change from the previous phase of the carbon pricing policy.

perfectly competitive outcome, when firms strategically interact, the price effect becomes larger at higher levels of demand because the execution of market power increases. Similar to the perfectly competitive outcome, the emissions reductions are smaller at higher demand levels when higher cost natural gas units are marginal and coal is dispatched under both SGER15 and CCR.

Table 9: Price and Emissions Changes Under Cournot Competition by Quartiles of Demand

\begin{tabular}{cccccccccc}
\hline & \multicolumn{4}{c}{ Change in Average Price } & & \multicolumn{4}{c}{ Change in Average Emissions } \\
\cline { 2 - 4 } \cline { 8 - 10 } Scenario & Q1 & Q2 & Q3 & Q4 & & Q1 & Q2 & Q3 & Q4 \\
\hline SGER17 & 3.49 & 3.64 & 3.63 & 4.48 & & -99 & -111 & -96 & -74 \\
CCR & 6.77 & 7.78 & 9.90 & 11.95 & & -463 & -486 & -416 & -314 \\
\hline
\end{tabular}

Notes: Price changes are given in $\$ / M W h$ and emissions changes in $\mathrm{tCO}_{2} \mathrm{e}$. Changes in emissions and prices represent the absolute change from the previous phase of the carbon pricing policy.

The mechanism through which the carbon pricing passes through to the electricity price is different and more complicated under the Cournot model. Unlike perfect competition, there is no clear difference in the degree and nature of price pass-through by year or demand level. In general, pass-through under Cournot competition reflects strategic behaviour on the part of the major firms rather than simply demand and the marginal technology in the market. In Alberta, most coal assets are owned by the major firms, while the competitive fringe is almost exclusively natural gas and cogeneration. The price pass-through and emissions effects in this setting depend on which technology the major firms are withholding (their firm-specific marginal technology) and the capacity utilization of the competitive fringe.

Figure 6 illustrates the relationship between the hourly price effect of going from the SGER15 to CCR for the entire sample by market demand, highlighting hours where the fringe's capacity utilization rate is at the top 10th percentile. Under Cournot competition, we observe price changes in the range observed under perfect competition at low demand hours. This reflects either the large firms' coal units setting the market price are subject to minimum stable generation constraints, firms are potentially over committed in the forward market in these hours, or there is excess fringe production capacity inducing the large firms to behave competitively.

For domestic output levels between 7,000 MWh and 8,500 MWhs, price pass-through is highly variable, ranging from pass-though of less than $\$ 0$ up to over $\$ 60$. The highest pass-through hours arise when the fringe's capacity is constrained and the large strategic firms are exercising a sizable amount of market 
Figure 6: Price Change By SGER15 Output, Cournot Competition, 2014 and 2015

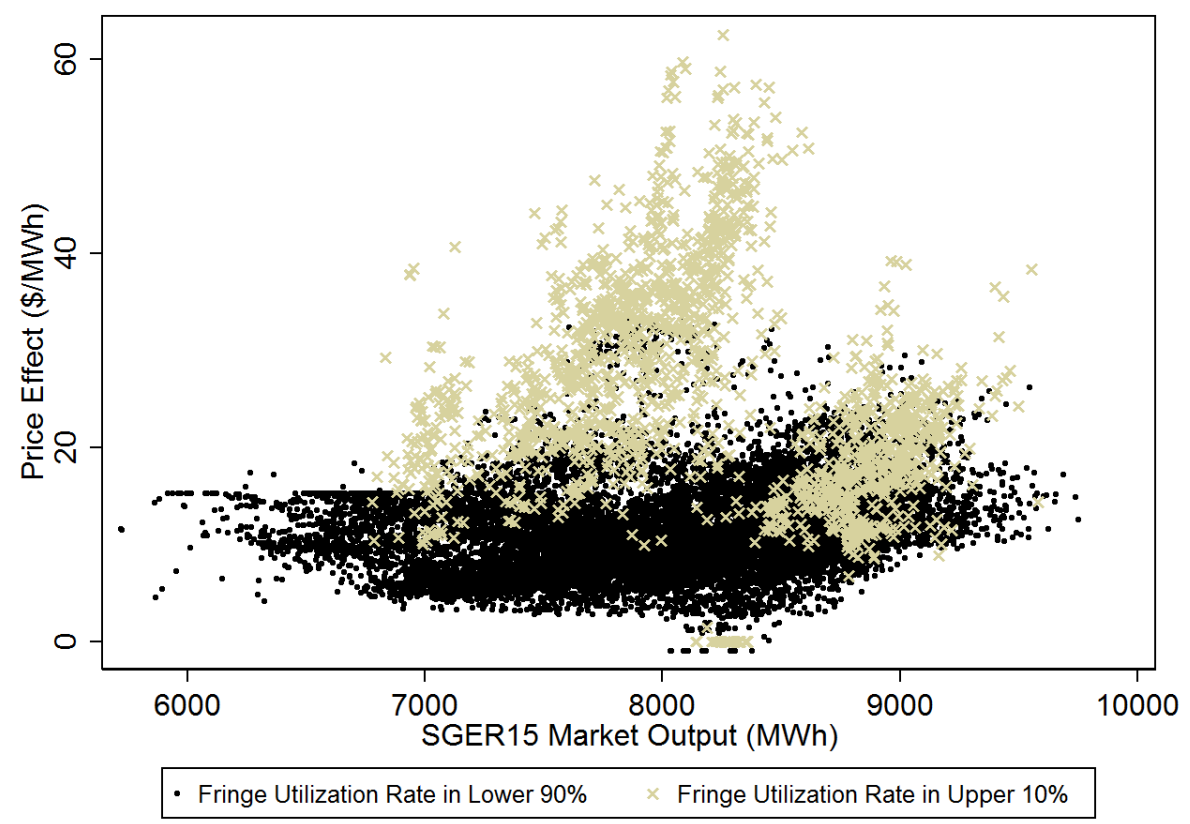

power. ${ }^{34}$ The low price effects arise in hours where natural gas is the marginal technology of the large firms, the cleanest of which have lower marginal costs under CCR than under SGER15. Finally, for the highest levels of output (i.e., above 8,500 MWhs), the fringe is often fully utilized and low cost natural gas is marginal. Carbon pricing therefore has a small and even negative effect on marginal costs. Therefore, the pass-through rate is high relative to the increase in marginal cost of these gas assets because residual demand is highly inelastic and the large firms exercise substantial market power by withholding output.

Figure 7 illustrates the price effect by fringe capacity utilization. Pass-through is less than $\$ 20$ for fringe utilization rates less than 0.9 , then dramatically increases as the fringe becomes fully utilized and the residual demand facing the Cournot competitors becomes increasingly inelastic. Similar patterns are observed in 2014 and 2015, although the lower demand and increased low cost natural gas capacity in 2015 makes pass-through lower and more uniform at all fringe utilization levels less than 0.98.

The predicted emissions reductions under Cournot-Nash competition are again determined by reductions in output and the degree of fuel substitution. However, the change in emissions now also reflect strategic behaviour. Similar to the perfectly competitive model, the emissions reductions predicted in 2015 are larger than those in 2014, reflecting the higher natural gas capacity and the lower fringe utilization. The reduction in emissions remains higher in the lower demand range where there is a higher degree of fuel substitution. At the high demand levels, emissions reductions are small because there is limited scope for fuel switching between coal and gas.

\subsection{Profits}

We have demonstrated that the carbon pricing policies have differential effects on coal and natural assets, with the degree of fuel switching depending on demand conditions and market structure assumptions. As

\footnotetext{
${ }^{34}$ Brown and Olmstead (2017) provide evidence that firms exercise a sizable amount of market power in Alberta when there is limited excess production capacity in the market causing the industry supply curve to become highly inelastic.
} 
Figure 7: Price Change by Fringe Utilization, Cournot Competition

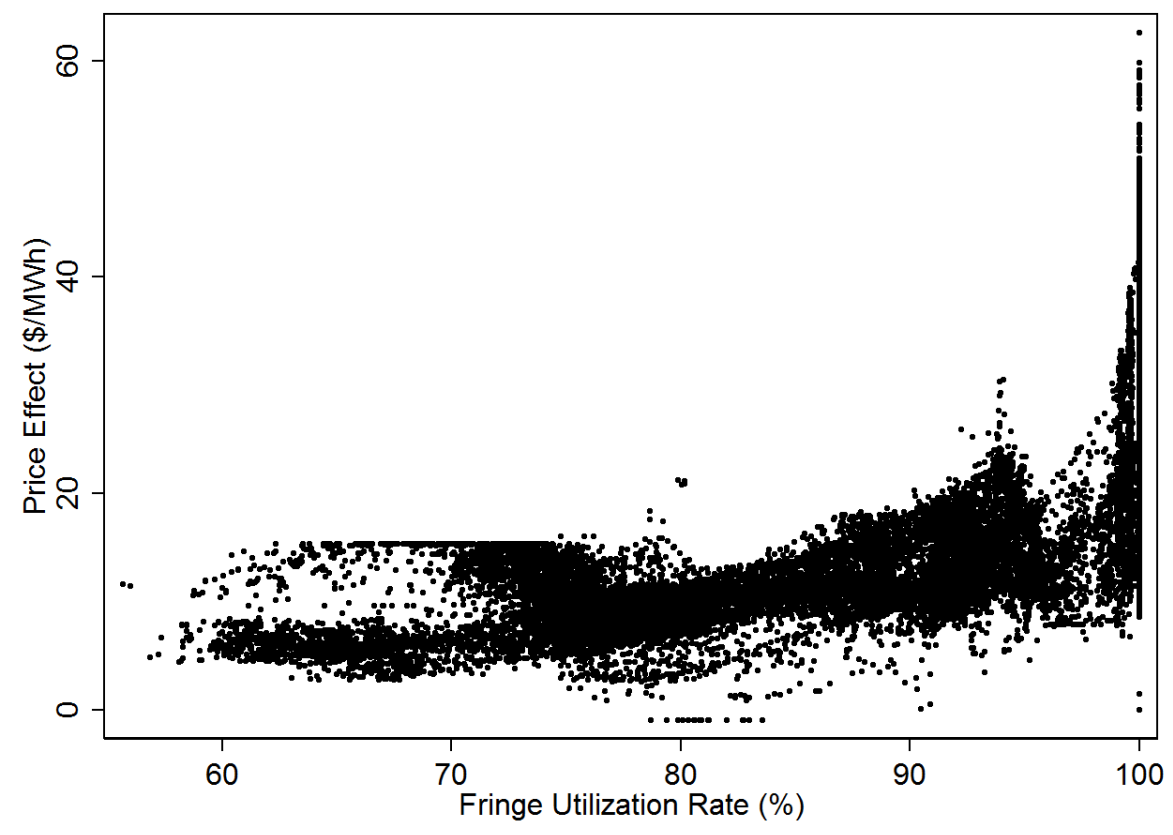

a result, the effect of carbon pricing on individual firm's variable profits is ambiguous because each firm has a diverse generation portfolio containing multiple technologies. This is in contrast with the findings of Sijm et al. (2006b), who find that allowance allocation under the EU ETS generates windfall profits for all power companies.

Table 10 reports average firm-level annual variable profits (in millions of CAD) across both years of our sample. ${ }^{35}$ In the Cournot model the transition from SGER15 to SGER17 appears to increase the profits of all firms besides Capital Power whose profits marginally decrease. However, the transition from SGER17 to CCR makes ATCO, ENMAX, the Fringe, and TransAlta better off, but reduces the profits of Capital Power and TransCanada. This arises because Capital Power and TransCanada's generation portfolios are dominated by coal generation capacity (see Table 1).

Table 10: Average Annual Profits by Carbon Pricing Scenario and Competition Structure

\begin{tabular}{ccccccccc}
\hline & \multicolumn{3}{c}{ Cournot } & & & \multicolumn{3}{c}{ Perfect Competition } \\
\cline { 2 - 4 } \cline { 7 - 9 } Firm & SGER15 & SGER17 & CCR & & & SGER15 & SGER17 & CCR \\
\hline ATCO & 235.09 & 248.44 & 278.88 & & & 90.92 & 102.29 & 135.89 \\
Capital Power & 248.94 & 248.48 & 241.71 & & 56.17 & 53.45 & 50.26 \\
ENMAX & 268.95 & 271.74 & 303.47 & & & 40.54 & 38.57 & 76.64 \\
FRINGE & 881.84 & 943.34 & $1,100.51$ & & 320.8 & 366.15 & 507.05 \\
TransAlta & 332.13 & 348.37 & 383.78 & & 121.37 & 134.36 & 170.19 \\
TransCanada & 388.69 & 392.31 & 377.85 & & 106.98 & 103.67 & 90.38 \\
\hline
\end{tabular}

Notes: Variable profits are in millions of CAD.

Similar ambiguity emerges in the competitive model, with certain firms increasing profit and others decreasing. Like the Cournot model, under perfect competition Capital Power and TransCanada's profits

\footnotetext{
${ }^{35}$ Similar conclusions arise when the results are decomposed by year.
} 
decrease due to the introduction of both policies. Under both forms of market competition, firms with a large number of natural gas and zero variable cost must-run assets (e.g., ATCO, TransAlta, and the Fringe) see a sizable increase in profits, particularly under the CCR policy.

Given the unique treatment of coal assets under CCR and the stated goal of coal elimination by 2030 (Alberta Energy, 2016), it is interesting to examine how coal unit profitability changes relative to the change in profits of other units. Table 11 reports the aggregate variable profits, in millions of CAD, from all coal units and all other units (excluding must-run wind and cogeneration) under the three scenarios by year. Regardless of the model of competition, coal profitability falls and natural gas profitability increases. As anticipated, this effect is particularly pronounced as we move to CCR. The reduction in coal unit profitability is more pronounced in 2015 because of the entry of low cost natural gas generation capacity, historically low gas prices, and lower market demand in Alberta. In fact, under the perfectly competitive outcome, coal units operate for a loss in our model in 2015 under the CCR policy. ${ }^{36}$

Table 11: Aggregate Variable Profits by Generation Technology

\begin{tabular}{ccccccccc}
\hline & & \multicolumn{3}{c}{ Cournot } & & \multicolumn{3}{c}{ Perfect Competition } \\
\cline { 3 - 5 } \cline { 7 - 9 } Asset Type & Year & SGER15 & SGER17 & CCR & & SGER15 & SGER17 & CCR \\
\hline \multirow{2}{*}{ Coal } & 2014 & $1,599.67$ & $1,594.98$ & $1,481.64$ & & 314.76 & 280.61 & 155.00 \\
& 2015 & 641.99 & 612.08 & 409.64 & & 76.50 & 51.61 & -0.83 \\
\hline \multirow{2}{*}{ Non-Coal } & 2014 & 244.83 & 274.23 & 582.48 & & 1.66 & 4.30 & 159.99 \\
& 2015 & 102.50 & 121.72 & 339.76 & & 102.50 & 121.72 & 339.76 \\
\hline
\end{tabular}

Notes: Non-coal generation units primarily represent natural gas generation assets. Variable profits are in millions of CAD.

\subsection{Robustness}

In this section we discuss the robustness of our results to two changes. First, our results are based on monthly firm-specific calibrated forward positions for peak and off-peak hours. Firm's incentives to exercise market power depend on their level of forward contracting (Bushnell et al., 2008, Brown and Eckert, 2016). To ensure our results are robust to adjustments to firms' forward positions, we rerun our analysis considering both a $5 \%$ percent increase and decrease in the forward positions of the five large firms. This places our calibrated forward positions near the top and bottom of those estimated in other studies (e.g., Hortascu and Puller, 2008; Bushnell et al., 2008; Reguant, 2014).

As expected, the price is higher (lower) when forward positions are reduced (increased) because firms have a stronger (weaker) incentive to exercise market power. Emissions are in turn also lower (higher) when forward positions are reduced (increased) because the large firms withhold more (less) output from relatively dirty generation assets. Our qualitative results regarding carbon pricing remain unchanged. The change in the nature of the output-based allocation still has a substantially larger effect on prices and emissions than the doubling of the carbon price. The general relationship between the hourly price effect by market demand is similar to that in Figure 6. However, when the fringe's capacity becomes fully

\footnotetext{
${ }^{36}$ Coal assets must satisfy minimum stable generation constraints and so, they can produce output at prices that are below their marginal cost of production. In practice, coal plants would consider retiring or mothballing their assets in this setting. For example, ENMAX has cited the CCR policy as a primary motivator behind their decision to exit its associated with coal power production (Balancing Pool, 2016).
} 
utilized, the price pass-through is over $\$ 70$ and approximately $\$ 50$ when the forward position is reduced and increased, respectively.

Second, we make adjustments to the level of natural gas prices. Our results are based on natural gas prices during our sample, which are historically low. For example, in 2015, natural gas spot prices in the U.S. were between $\$ 2$ and $\$ 3$ compared to prices over $\$ 10$ in 2006 and 2008 (EIA, 2017). Moreover, there is substantial variability in predictions of future spot prices for natural gas. We rerun our analysis, considering a 30\% increase and decrease in the hourly natural gas price. As expected, regardless of competition, average price and emissions are higher (lower) when natural gas prices are higher (lower). Similar to our main analysis, changing the nature of the output-based subsidy has a substantially larger effect on prices and emissions than the doubling of the carbon price. Under perfect competition, the relationship between the price effect and market output is similar. However, the proportion of observations in the three groups illustrated in Figures 4 and 5 change. When natural gas prices are high (low), coal is marginal before and after carbon pricing in a larger (smaller) proportion of hours. Under Cournot competition, our results are essentially unchanged.

\section{Concluding Remarks}

In this paper we explore how different forms of carbon pricing affect wholesale electricity prices, output, and emissions in the short-run and how these effects differ under perfect and imperfect competition. We consider the case study of Alberta, which introduced a unique carbon pricing regime. In the first phase of the policy, the per tonne price of carbon is doubled. While in the second phase, the output-based subsidy was changed from being based on a facility-level baseline emissions intensity to the emissions intensity of a benchmark natural gas unit, keeping the price of carbon constant. This policy allows us to examine the price and emissions responses to these two types of carbon pricing changes.

The main conclusions of the paper are as follows. First, changing the nature of the output-based subsidy has substantially larger price effects and emissions reductions than doubling the price of carbon. Asymmetrically increasing the costs of coal generation leads to a larger degree of fuel substitution. Second, the presence of market power and the distribution of dirty assets across firms has major implications on the price and emissions effects of carbon pricing policies. Most analyses that attempt to analyze the impacts of a carbon pricing policy in electricity markets use a least-cost (perfectly competitive) dispatch model. We illustrate that market power can generate large differences in market outcomes.

Under perfect competition, the degree of pass-through and reductions in emissions are determined by the level of market demand and the technology of the marginal asset before and after the carbon pricing change. In contrast, under Cournot competition, factors such as the distribution of technologies across large and fringe firms as well as the utilization of the fringe's generation capacity are important determinants of pass-through and emissions reductions. As such, it is important for policy analysts to carefully consider the degree of market competition in regulated industries. As well, anticipated changes in market concentration, either because of the policy or exogenous factors, should be accounted for in

policy development. For example, as electricity markets transition away from coal generation toward renewables and natural gas, market concentration will likely change.

Regardless of market structure, changing the basis of the output-based subsidy has a substantially 
larger effect on prices and emissions than increasing the per tonne carbon price. By asymmetrically increasing compliance costs for the dirtiest generators, the CCR policy leads to greater fuel switching, generating larger emissions reductions, holding all other factors constant. This has implications on understanding the price and emissions effects of carbon pricing policies worldwide as markets consider implementing carbon pricing policies. This analysis is particularly relevant for regions with market-based electricity markets with a sizable amount of coal and natural gas assets (e.g., the Midwestern and Southeastern United States). More generally, our results suggest that when regulators use output subsidization to reduce the cost burden of emissions pricing, the form of that subsidy can have important implications for the efficacy of the emissions policy. In our setting, defining the subsidy paid to all firms in terms of a benchmark asset leads to much greater emissions reductions than simply reducing the percentage of historical baseline intensity, albeit with larger price increases.

There are several potential directions for future research. First, an examination of the entry and exit decisions of generating assets of different technologies is necessary to understand the long-run implications of carbon pricing coupled with output-subsides in the electricity industry. Our analysis takes the number and identities of generating assets as given, but suggests (in our discussion of profitability) that the exit of coal assets would be expected. Other avenues for continuing research concern the combination of carbon pricing with other policies. Alberta has indicated the intention of introducing a capacity market and renewable procurement auction to facilitate the integration of renewable generation. The first capacity auctions are expected to begin in 2019 (AESO, 2016). While these changes are not expected to affect our short-run analysis, they are important in understanding the long-run implications for entry and exit. In addition, in contrast to the current design in Alberta, most restructured electricity markets with capacity markets also feature some form of bid mitigation in order to limit market power. The introduction of such bid mitigation, which to our knowledge has not yet been proposed, could change the short-run predictions in our Cournot analysis. 


\section{References}

AESO (2016). Alberta's Wholesale Electricity Market Transition Recommendation. Alberta Electric System Operator.

Alberta Energy (2014). Coal Statistics. Available at: http://www.energy.alberta.ca/coal/643.asp

Alberta Energy (2016). Phase-Out of Coal-Fired Emissions in Alberta. Available at: http://www. energy.alberta.ca/Org/pdfs/FSCoalPhaseOut.pdf

AUC (2016). Annual Electricity Data. Alberta Utility Commission. Available at: http://www.auc.ab.ca/ market-oversight/Annual-Electricity-Data-Collection/Pages/default.aspx

Balancing Pool (2016). Battle River 5 PPA - Buyer Termination. Available at: http://www.balancingpool. ca/news-releaseshttpwww-balancingpool-cawp-contentuploads201304news-release-board-resignations-doc/.

Baldick, R., R. Grant, and E. Kahn (2004). "Theory and Applications of Linear Supply Function Equilibrium in Electricity Markets," Journal of Regulatory Economics, 25(2): 143 - 167.

Borenstein, S. and J. Bushnell (1999). "An Empirical Analysis of the Potential for Market Power in California's Electricity Market," Journal of Industrial Economics, 47(3): 285 - 323.

Borenstein, S., J. Bushnell and C. Knittel (1999). "Market Power in Electricity Markets: Beyond Concentration Measures," The Energy Journal, 20: 65-88.

Borenstein, S., Bushnell, J., and F. Wolak. (2002). "Measuring Market Inefficiencies in California's Restructured Wholesale Electricity Market," American Economic Review, 92(5): 1376 - 1405.

Brown, D. and A. Eckert (2016). "Analyzing the Impact of Electricity Market Structure Changes and Mergers: The Importance of Forward Commitments," University of Alberta Working Paper.

Brown, D. and A. Eckert (2017). "Electricity Market Mergers with Endogenous Forward Contracting," University of Alberta Working Paper.

Brown, D. and D. Olmstead (2017). "Measuring Market Power and the Efficiency of Alberta's Restructured Electricity Market: An Energy-Only Market Design," Canadian Journal of Economics, Forthcoming.

Bushnell, J., Mansur, E., and C. Saravia (2008). "Vertical Arrangements, Market Structure, and Competition: An Analysis of Restructured Electricity Markets," American Economic Review, 98(1): 237 266.

CASA (2004). A Study on the Efficiency of Alberta's Electrical Supply System. Project \# CASA-EEEC02-04. Clean Air Strategic Alliance. Prepared by JEM Energy.

Crew, M. and P. Kleindorfer (2002). "Regulatory Economics: Twenty Years of Progress?" Journal of Regulatory Economics, 21(1): 5 - 22.

Czyzyk, J., Mesnier, M., and J. More (1998). "The NEOS Server," IEEE Journal of Computational Science and Engineering, 5(3): 68 - 75. 
EIA (2016). Levelized Cost and Levelized Avoided Cost of New Generation Resources in the Annual Energy Outlook 2016. Energy Information Administration.

EIA (2017). Henry Hub Natural Gas Spot Prices. Energy Information Administration. Accessed: January 10, 2017.

EPA (2016). Inventory of U.S. Greenhouse Gas Emissions and Sinks: 1990 - 2014. U.S. Environmental Protection Agency.

Eurostat (2016). Greenhouse Gas Emissions by Industries and Households. Available at: http://ec. europa.eu/eurostat/statistics-explained/index.php/Greenhouse_gas_emissions_by_industries_and_households\# Analysis_by_economic_activity

Fabra, N. and M. Reguant. (2014) "Pass-Through of Emissions Costs in Electricity Markets," The American Economic Review, 104(9): 2872-2899.

Ferris, M. and T. Munson (2000). "Complementarity Problems in GAMS and the PATH Solver," Journal of Economic Dynamics and Control, 24(2): 165-188.

Fischer, C. (2001). "Rebating Environmental Policy Revenues: Output Based Allocations and Tradable Performance Standards," Resources for the Future Discussion Paper 01-22.

Fischer, C. (2011). "Market Power and Output Based-Refunding of Environmental Policy Revenues," Resource and Energy Economics, 33: 212-230.

Fowlie, M. and J. Perloff (2013). "Distributing Pollution Rights in Cap-and-Trade Programs: Are Outcomes Independent of Allocation?" The Review of Economics and Statistics, 95(5): 1640-1652.

Fowlie, M., M. Reguant, and S. Ryan (2016). "Market-Based Emissions Regulation and Industry Dynamics," Journal of Political Economy, forthcoming.

Frutos, M. and N. Fabra (2012). "How to Allocated Forward Contracts: The Case of Electricity Markets," European Economic Review, 56(3): 451 - 469.

Gersbach, H. and T. Requate (2004). "Emissions Taxes and Optimal Refunding Schemes," Journal of Public Economics, 88: 713-725.

Golombek, R., S. Kittelsen, and K. Rosendahl (2012). "Price and Welfare Effects of Emission Quota Allocation," Statistics Norway Discussion Paper No. 661.

Government of Alberta (2015). Climate Leadership Report to the Minister. Available at: https://www. alberta.ca/documents/climate/climate-leadership-report-to-minister.pdf

Hortascu, A. and S. Puller (2008). "Understanding Strategic Bidding in Multi-Unit Auctions: A Case Study of the Texas Electricity Spot Market," RAND Journal of Economics, 39(1): 86 - 114.

Klemperer, P. and M. Meyer (1989). "Supply Function Equilibria in Oligopoly under Uncertainty," Econometrica, 57(6): 1243 - 1277.

Kolstad, C. and L. Mathiesen (1991). "Computing Cournot-Nash Equilibria," Operations Research, 39(5): $739-748$. 
Leach, A. (2012). "Policy Forum: Alberta's Specified Gas Emitters Regulation," Canadian Tax Journal, 60: $881-898$.

Levin, D. (1985). "Taxation with Cournot Oligopoly," Journal of Public Economics, 27: 281-290.

Mackinnon, J., White, H., and R. Davidson (1983). "Tests for Model Specification in the Presence of Alternative Hypotheses," Journal of Econometrics, 21: 53-70.

Mansur, E. (2007). "Do Oligopolists Pollute Less? Evidence from a Restructured Electricity Market," The Journal of Industrial Economics, 55(4): 661 - 689.

MSA (2010). An Introduction to Alberta's Financial Electricity Market. Alberta Market Surveillance Administrator.

MSA (2011). Offer Behaviour Enforcement Guidelines for Alberta's Wholesale Electricity Market. Alberta Market Surveillance Administrator.

MSA (2012). State of the Market Report 2012: An Assessment of Structure, Conduct, and Performance of Alberta's Wholesale Electricity Market. Alberta Market Surveillance Administrator.

MSA (2014). Market Share Offer Control 2014. Alberta Market Surveillance Administrator.

MSA (2015). Market Share Offer Control 2015. Alberta Market Surveillance Administrator.

NERC (2016). Generating Unit Statistical Brochure 4 - 2014. Generating Availability Data System. North American Electric Reliability Corporation. Available at: http://www.nerc.com/pa/RAPA/gads/Pages/ Reports.aspx

Neuhoff, K., Barquin, J., Bialek, J., Boyd, R., Dent, C., Echavarren, F., Grau, T., von Hirschhausen, C., Hobbs, B., Kunz, F., Nabe, C., Papaefthymiou, G., Weber, C., and H. Weight (2013). "Renewable Electric Energy Integration: Quantifying the Value of Design of Markets for International Transmission Capacity," Energy Economics, 40: 760 - 772.

Newcomer, A., S. Blumsack, J. Apt, L. Lave, and M. Morgan (2008). "Short Run Effects of a Price on Carbon Dioxide Emissions from the U.S. Electric Generators," Environmental Science $\&$ Technology, 42(9): 3139 - 3144.

Paul, A., K. Palmer, and M. Woerman (2013). "Modeling a Clean Energy Standard for Electricity: Policy Design Implications for Emissions, Supply, Prices, and Regions," Energy Economics, 36: 108 - 124.

Pesaran, M. and R. Smith. (1983). "A Generalized R ${ }^{2}$ Criterion for Regression Models Estimated by the Instrumental Variables Method," Econometrica, 63(3): 705-710.

Pfeifenberger, J., Spees, K., and A. Schumacher (2009) A Comparison of PJM's RPM with Alternative Energy and Capacity Market Designs. The Brattle Group.

RBB Economics (2014). Cost Pass-Through: Theory, Measurement and Potential Policy Implications. Prepared for the Office of Fair Trading.

Reguant, M (2014). "Complementary Bidding Mechanisms and Startup Costs in Electricity Markets," Review of Economic Studies, 81(4): 1708 - 1742. 
Requate, Till. (2006) Environmental Policy Under Imperfect Competition. The International Yearbook of Environmental and Resource Economics 2007: 120-207.

Rivers, N. and M. Jaccard. (2010). "Intensity-Based Climate Change Policies in Canada," Canadian Public Policy, 36(4): 409-428.

Sijm, J., S. Bakker, H. Harmsen, W. Lise, and Y. Chen. (2006a) "CO2 Price Dynamics. The Implications of EU Emissions Trading for Electricity Prices and Operations." No. ECN-M-06-084. Energy Research Centre of the Netherlands ECN.

Sijm, J., K. Neuhoff, and Y. Chen (2006b). "CO2 Cost Pass-Through and Windfall Profits in the Power Sector," Climate Policy, 6(1): 49-72.

Sijm, J., Y. Chen and B. Hobbs (2012). "The Impact of Power Market Structure on CO2 Cost PassThrough to Electricity Prices Under Quantity Competition - A Theoretical Approach," Energy Economics, 34: $1143-1152$.

Sterner. T. and L. Isaksson (2006). "Refunded Emissions Payments Theory, Distribution of Costs, and Swedish Experience of $\mathrm{NO}_{x}$ Abatement," Ecological Economics, 57(1): 93-106.

Ventosa, M., A. Baillo, A. Ramos, and N, Rivier (2005). "Electricity Market Modeling Trends," Energy Policy, 33(7): 897 - 913.

Weyl, E. G. and M. Fabinger (2013). "Pass-Through as an Economic Tool: Principles of Incidence under Imperfect Competition," Journal of Political Economy, 121: 528-583. 


\section{Appendix}

\section{A Marginal Cost Estimation}

Data on natural gas unit heat rates were obtained from Alberta's Market Surveillance Administrator, the Alberta Utility Commission, and the Alberta Electric System Operator. Coal unit heat rates were obtained from CASA (2004). Data on technology-specific variable O\&M costs were obtained from the Energy Information Administration (EIA, 2016). Hourly natural gas prices were obtained from Alberta's Natural Gas Exchange. We use weekly coal prices from Wyoming's Powder River Basin (PRB) from the Energy Information Administration to estimate the marginal cost of coal units in Alberta. ${ }^{37}$ PRB coal is sub-bituminuous coal which is the primary coal used for electricity generation in Alberta. Further, PRB coal and Alberta's sub-bituminuous coal have similar heat-rate contents (Alberta Energy, 2014). Using Bank of Canada exchange rates, we adjusted the PRB coal prices and USD based variable O\&M costs from USD to CAD. We obtained unit-level nameplate generation capacity from MSA $(2014,2015)$. Derated forced outage statistics were obtained from the North American Electric Reliability Corporation's Generation Availability Data System Reports (NERC, 2016).

\section{B Import Supply and Residual Demand Estimation}

After import decisions are made, importers are required to submit bids equal to $\$ 0$ into Alberta's wholesale market. While importers are price-takers in the spot market, they form expectations about the expected uniform spot market price when making their import supply decisions. Table A1 details the provincespecific price-responsive import supply function estimation results for the linear-log model specification. The OLS estimates in Table A1 illustrate that a failure to control for the endogeneity of price yields the anticipated attenuation bias. We use two tests to choose the model specification for the import supply functions between linear, linear-log, and log-log. First, we use the PE test established by Mackinnon et al. (1983). For both provinces, the PE tests finds that the linear-log specification is superior to linear and log-log. Second, we use a Generalized R-Squared (GR2) measure established by Pesaran and Smith (1983) to test the goodness-of-fit of each specification. For both provinces, the linear-log specification provides a better fit (higher GR2) than the linear and log-log specifications.

\footnotetext{
${ }^{37}$ Using 2008 - 2014 data from Alberta's wholesale electricity market, Brown and Olmstead (2017) use a Monte-Carlo approach that selects unit-specific non-zero coal bids into the wholesale market in low demand hours to represent each coal unit's marginal costs. The authors illustrate that their Monte-Carlo methodology results in marginal cost estimates that closely reflect estimates obtained using $\mathrm{PRB}$ coal prices and coal unit heat rates in Alberta.
} 
Table A1: Hourly Import Supply Function IV Estimation

\begin{tabular}{|c|c|c|c|c|c|c|}
\hline & \multicolumn{3}{|c|}{ Saskatchewan } & \multicolumn{3}{|c|}{ British Columbia } \\
\hline & $\begin{array}{c}\text { OLS } \\
Q_{S K, t}^{I M}\end{array}$ & $\begin{array}{l}\text { First Stage } \\
\quad \ln \left(p_{t}\right)\end{array}$ & $\begin{array}{c}\text { Second Stage } \\
Q_{S K, t}^{I M}\end{array}$ & $\begin{array}{c}\text { OLS } \\
Q_{B C, t}^{I M}\end{array}$ & $\begin{array}{l}\text { First Stage } \\
\quad \ln \left(p_{t}\right)\end{array}$ & $\begin{array}{c}\text { Second Stage } \\
Q_{B C, t}^{I M}\end{array}$ \\
\hline$\overline{\ln \left(p_{t}\right)}$ & $\begin{array}{l}5.66^{* * *} \\
(0.52)\end{array}$ & - & $\begin{array}{l}12.44^{* * *} \\
(2.64)\end{array}$ & $\begin{array}{l}61.01^{* * *} \\
(2.66)\end{array}$ & - & $\begin{array}{l}295.60^{* * *} \\
(23.58)\end{array}$ \\
\hline Import $\mathrm{Cap}_{j}$ & $\begin{array}{l}0.09^{* * *} \\
(0.002)\end{array}$ & $\begin{array}{l}-0.0005^{* *} \\
(0.0002)\end{array}$ & $\begin{array}{l}0.08^{* * *} \\
(0.008)\end{array}$ & $\begin{array}{l}0.14^{* * *} \\
(0.005)\end{array}$ & $\begin{array}{l}-0.00002 \\
(0.00005)\end{array}$ & $\begin{array}{l}0.125^{* * *} \\
(0.019)\end{array}$ \\
\hline $\mathrm{HDD}_{j}$ & $\begin{array}{l}-0.20^{* * *} \\
(0.07)\end{array}$ & $\begin{array}{l}-0.008^{* *} \\
(0.004)\end{array}$ & $\begin{array}{l}-0.16 \\
(0.205)\end{array}$ & $\begin{array}{l}15.03^{* * *} \\
(1.02)\end{array}$ & $\begin{array}{l}-0.026^{* * *} \\
(0.009)\end{array}$ & $\begin{array}{l}22.76^{* * *} \\
(3.54)\end{array}$ \\
\hline $\mathrm{HDD}_{j}^{2}$ & $\begin{array}{c}0.002^{*} \\
(0.0012)\end{array}$ & $\begin{array}{l}0.0002^{* * *} \\
(0.00008)\end{array}$ & $\begin{array}{l}-0.0004 \\
(0.004)\end{array}$ & $\begin{array}{l}-0.64^{* * *} \\
(0.042)\end{array}$ & $\begin{array}{l}0.0015^{* * *} \\
(0.0004)\end{array}$ & $\begin{array}{l}-1.19^{* * *} \\
(0.16)\end{array}$ \\
\hline $\mathrm{CDD}_{j}$ & $\begin{array}{l}-0.12 \\
(0.42)\end{array}$ & $\begin{array}{l}0.044^{* *} \\
(0.022)\end{array}$ & $\begin{array}{l}-0.71 \\
(0.81)\end{array}$ & $\begin{array}{l}38.43^{* * *} \\
(4.04)\end{array}$ & $\begin{array}{c}-0.03 \\
(0.033)\end{array}$ & $\begin{array}{l}34.29^{* * *} \\
(10.19)\end{array}$ \\
\hline $\mathrm{CDD}_{j}^{2}$ & $\begin{array}{c}0.07 \\
(0.05)\end{array}$ & $\begin{array}{c}-0.0004 \\
(0.003)\end{array}$ & $\begin{array}{c}0.08 \\
(0.08)\end{array}$ & $\begin{array}{l}-1.82^{* *} \\
(0.73)\end{array}$ & $\begin{array}{l}0.025^{* * *} \\
(0.007)\end{array}$ & $\begin{array}{l}-7.65^{* * *} \\
(1.87)\end{array}$ \\
\hline Weekday & $\begin{array}{l}1.32^{* * *} \\
(0.36)\end{array}$ & $\begin{array}{l}-0.12 \\
(0.20)\end{array}$ & $\begin{array}{c}0.53 \\
(0.99)\end{array}$ & $\begin{array}{l}32.17^{* * *} \\
(2.43)\end{array}$ & $\begin{array}{l}-0.11^{* * *} \\
(0.03)\end{array}$ & $\begin{array}{c}2.15 \\
(8.69)\end{array}$ \\
\hline Holiday & $\begin{array}{l}1.08 \\
(1.16)\end{array}$ & $\begin{array}{l}-0.01 \\
(0.07)\end{array}$ & $\begin{array}{c}2.45 \\
(3.73)\end{array}$ & $\begin{array}{l}-41.19^{* * *} \\
(6.57)\end{array}$ & $\begin{array}{l}-0.037 \\
(0.07)\end{array}$ & $\begin{array}{c}12.49 \\
(23.45)\end{array}$ \\
\hline Demand & - & $\begin{array}{l}5.72^{* * *} \\
(0.46)\end{array}$ & - & - & $\begin{array}{l}5.65^{* * *} \\
(0.42)\end{array}$ & - \\
\hline Constant & $\begin{array}{l}-21.66^{* * *} \\
(2.10)\end{array}$ & $\begin{array}{l}-48.71^{* * *} \\
(4.17)\end{array}$ & $\begin{array}{l}-41.99^{* * *} \\
(9.78)\end{array}$ & $\begin{array}{l}-204.21^{* * *} \\
(12.23)\end{array}$ & $\begin{array}{l}-47.97^{* * *} \\
(3.77)\end{array}$ & $\begin{array}{c}-956.86^{* * *} \\
(81.18)\end{array}$ \\
\hline$R^{2}$ & 0.39 & - & - & 0.56 & - & - \\
\hline K-P Wald F-Stat & - & $154.55^{* * *}$ & - & - & $184.26^{* * *}$ & - \\
\hline Sample Size & 17,520 & 17,520 & 17,520 & 17,520 & 17,520 & 17,520 \\
\hline Hour-Month-Year Controls & $\mathrm{Y}$ & $\mathrm{Y}$ & $\mathrm{Y}$ & $\mathrm{Y}$ & $\mathrm{Y}$ & $\mathrm{Y}$ \\
\hline
\end{tabular}

Notes: Each regression includes hour, month, and year covariates. K-P Wald F-Stat denotes the Kleibergen-Paap Wald F-Statistic. The temperature variables contain heating degree days (HDD) and cooling degree days (CDD) for Vancouver

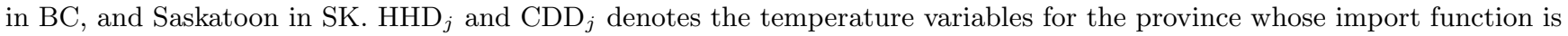
being estimated (i.e., $j \in\{B C, S K\}$ ). Demand denotes the exclusive instrument day-ahead forecasted demand. The OLS regression reflects Newey-West heteroskedastic and autocorrelation robust standard errors with 24 lags.

$* * *, * *$, and $*$ indicate statistically significant coefficients at the $1 \%, 5 \%$, and $10 \%$ percent levels, respectively. 


\section{Department of Economics, University of Alberta Working Paper Series}

2016-18: Monetary Policy Tradeoffs Between Financial Stability and Price Stability Shukayev, M., Ueberfeldt, A.

2016-17: Managing Risk Taking with Interest Rate Policy and Macroprudential Regulations Cociuba, S., Shukayev, M., Ueberfeldt, A.

2016-16: On the Role of Maximum Demand Charges in the Presence of Distributed Generation Resources - Brown, D., Sappington, D.

2016-15: Implementing Cross-Border Interbank Lending in BoC-GEM-FIN - Shukayev, M., Toktamyssov, A.

2016-14: The Effects of Early Pregnancy on Education, Physical Health and Mental Distress: Evidence from Mexico - Gunes, P., Tsaneva, M.

2016-13: An Equilibrium Selection Theory of Monopolization - Eckert, A., Klumpp, T., Su, $\mathbf{x}$.

2016-12: Education Curriculum and Student Achievement: Theory and Evidence - Andrietti, V., Su, $\mathbf{X}$.

2016-11: Poverty and Aging - Marchand, J., Smeeding, T.

2016-10: Local Labor Markets and Natural Resources: A Synthesis of the Literature Marchand, J., Weber, J.

2016-09: Accounting for Firm Exit and Loss of Variety in the Welfare Cost of Regulations Andersen, $D$.

2016-08: Analyzing the I mpact of Electricity Market Structure Changes and Mergers: The Importance of Forward Commitments - Brown, D., Eckert, A.

2016-07: Credibility of History-Dependent Monetary Policies and Macroeconomic Instability Cateau, G., Shukayev, M.

2016-06: Electricity Market Mergers with Endogenous Forward Contracting - Brown, D., Eckert, A.

2016-05: Thinking about Minimum Wage Increases in Alberta: Theoretically, Empirically, and Regionally - Marchand, J.

2016-04: Economic and Socio-Demographic Determinants of Child Nutritional Status in Egypt: A Comprehensive Analysis using Quantile Regression Approach- Sharaf,M., Rashad,A. 2016-03: Regional Inequalities in Child Malnutrition in Egypt, Jordan, and Yemen: A BlinderOaxaca Decomposition Analysis - Rashad, A., Sharaf, M.

2016-02: Collateralized Borrowing and Risk Taking at Low Interest Rates - Cociuba, S., Shukayev, M., Ueberfeldt, A.

2016-01: Optimal Policies to Promote Efficient Distributed Generation of Electricity - Brown, D., Sappington, D.

2015-18: Departure and Promotion of U.S. Patent Examiners: Do Patent Characteristics Matter? - Langinier, C., Lluis, S.

2015-17: Socioeconomic Inequalities in Infant Mortality in Egypt: Analyzing Trends between 1995 and 2014 - Sharaf, M., Rashad, A.

2015-16: Does Economic Growth Reduce Child Malnutrition in Egypt? New Evidence from National Demographic and Health Survey - Rashad, A., Sharaf, M.

2015-15: The Labor Market and School Finance Effects of the Texas Shale Boom on Teacher Quality and Student Achievement - Marchand, J., Weber, J.

2015-14: Measuring Market Power and the Efficiency of Alberta's Restructured Electricity Market: An Energy-Only Market Design - Brown, D., Olmstead, D.

2015-13: The Welfare and Stabilization Benefits of Fiscal Rules: Evidence from Canadian Provinces - Landon, S., Smith, C.

2015-12: Law and Economics and Tort Litigation Institutions: Theory and Experiments Landeo, C. 